\title{
VA/DoD CLINICAL PRACTICE GUIDELINE
}

\section{FOR MANAGEMENT OF CONCUSSION/ MILD TRAUMATIC BRAIN INJURY}

\author{
Department of Veterans Affairs \\ Department of Defense
}

Prepared by:

\section{The Management of Concussion/mTBI Working Group}

With support from:

The Office of Quality and Performance, VA, Washington, DC

$\&$

Quality Management Directorate, United States Army MEDCOM

Version 1.0 - 2009

\section{QUALIFYING STATEMENTS}

The Department of Veterans Affairs (VA) and The Department of Defense (DoD) guidelines are based upon the best information available at the time of publication. They are designed to provide information and assist decision-making. They are not intended to define a standard of care and should not be construed as one. Neither should they be interpreted as prescribing an exclusive course of management.

Variations in practice will inevitably and appropriately occur when providers take into account the needs of individual patients, available resources, and limitations unique to an institution or type of practice. Every healthcare professional making use of these guidelines is responsible for evaluating the appropriateness of applying them in the setting of any particular clinical situation.

DOI $: 10.1682 / J R R D .2009 .06 .0076$ 


\section{Introduction}

\section{Background}

The Centers for Disease Control and Prevention (CDC) has estimated that each year, approximately 1.5 million Americans survive a traumatic brain injury (TBI), among whom approximately 230,000 are hospitalized. Approximately 50,000 Americans die each year following traumatic brain injury, representing one third of all injury-related deaths. The leading causes of TBI are falls (28\%), motor vehicle-traffic accidents $(20 \%)$, struck by/against events $(19 \%)$ and assaults (11\%). It is estimated that of the total reported TBIs, the vast majority (75\%-90\%) of these fit the categorization of mild-TBI and that approximately ninety percent ( $90 \%)$ of these follow a predictable course and experience few, if any, ongoing symptoms and do not require any special medical treatment. More than 1.1 million patients with mTBI are treated and released from an emergency department each year. Only a small sub-set of these patients (10\%) experience post-injury symptoms of a long lasting nature.

The incidence of TBI has significantly increased in the patient population of the DoD and VHA as a result of injuries during recent military and combat operations. In the past 8 years, TBI has emerged as a common form of injury in service men and women serving in Operation Enduring Freedom (OEF) and Operation Iraqi Freedom (OIF). Although penetrating TBI is typically identified and cared for immediately, mTBI may be missed, particularly in the presence of other more obvious injuries. Due to numerous deployments and the nature of enemy tactics, troops are at risk for sustaining more than one mild brain injury or concussion in a short timeframe.

As experience with this condition in OEF and OIF service persons and veterans accumulated, it became clear that screening for possible TBI in OEF and OIF veterans could contribute to ensuring that patients are identified and treatment implemented.

In response to this need, VHA established a task force including members with expertise in Physical Medicine and Rehabilitation, Neurology, Psychiatry, Psychology, Primary Care, Prevention, and Medical Informatics to develop a screening tool and evaluation protocol. Although TBI is a significant public health problem, currently there are no validated screening instruments specific to TBI that are accepted for use in clinical practice. Therefore, the task force reviewed existing literature on screening for TBI, examined the efforts of individual military Medical Treatment Facilities (MTF's) and Department of Veterans Affairs (VA) Medical Centers that had implemented TBI screening locally, consulted with the Defense and Veterans Brain Injury Center (DVBIC), and considered data on the natural history of TBI. Based on these efforts, the task force developed a consensus document that included definitions, classification and taxonomy.

Following the development of a definition document, the task force constructed a screening instrument to assist in identifying OEF and OIF veterans who may be suffering from TBI, and a protocol for further evaluation and treatment of those whose screening tests are positive. Furthermore, a national electronic clinical reminder, VATBI Screening, was built incorporating this screening instrument. These protocols have been considered the seed for the development of this Evidence Based Practice Guideline. The DoD has published Clinical Guidance for Management of Mild-TBI in Theater and mTBI in Non-Deployed Medical Activities.

After the VA/DoD Working Group completed the review of the evidence for this guideline an Institute of Medicine (IOM) report addressing long-term consequences of Traumatic Brain Injury was published (IOM, 2009). The IOM committee concluded, on the basis of its evaluation, that there is limited/suggestive evidence of an association between sustaining a mild TBI resulting in loss of consciousness or amnesia and the development of unprovoked seizures, ocular and visual motor deterioration.

The committee found inadequate/insufficient evidence to determine whether an association exists between mild TBI and neurocognitive deficits and long-term adverse social functioning, including unemployment, diminished social relationships, and decrease in the ability to live independently.

For long-term outcomes, the IOM report describes limited/suggestive evidence of an association between mild TBI and Parkinson Disorder and between mild TBI and dementia of the Alzheimer's type when the injury included loss of consciousness. However, insufficient evidence of such association was found in mild TBI without loss of consciousness. 


\section{Scope of Guideline}

- This Evidence Based Guideline applies to adult patients (18 years or older) who are diagnosed with concussion/mTBI and complain of symptoms related to the injury and who are treated in VA/DoD clinical settings for these symptoms at least 7 days after the initial head injury.

- The guideline is relevant to all healthcare professionals providing or directing treatment services to patients with concussion/mTBI in any VA/DoD healthcare setting, including both primary and specialty care.

- This guideline does not address: management of concussion/mTBI in the acute phase $(<7$ days post injury), management of moderate or severe TBI, mTBI presented as polytrauma and managed in an inpatient setting, or mTBI in children.

\section{Development Process}

The development process of this guideline follows a systematic approach described in "Guideline-forGuidelines," an internal working document of VHA’s National Clinical Practice Guideline Counsel.

The literature search identified publications from 2002 through 2008 that addressed adult patients with mTBI. The initial year (2002) was elected to succeed the World Health Organization, (WHO) systematic review of publications related to mTBI conducted in 2002. The WHO Collaborating Centre for Neurotrauma Task Force on Mild Traumatic Brain Injury (Caroll, et al., 2004) performed a comprehensive search and critical review of the literature published between 1980 and 2002 to assemble the best evidence on the epidemiology, diagnosis, prognosis and treatment of mild traumatic brain injury.

The literature identified by the search was critically analyzed and graded using a standardized format applying the evidence grading system used by the U.S. Preventative Services Task Force. For recommendations that are based on evidence the strength of recommendation grade (SR) is included in brackets following the recommendations. Where existing literature was ambiguous or conflicting, or where scientific data were lacking on an issue, recommendations were based on the clinical experience of the members of the Working Group and are presented without an SR grade. 


\section{WORKING GROUP PARTICIPANTS}

\begin{tabular}{|c|c|}
\hline \multicolumn{2}{|c|}{ CONCUSSION/mTBI GUIDELINE WORKING GROUP } \\
\hline VA & DoD \\
\hline David Cifu, MD & Amy Bowles, MD \\
\hline Robin Hurley, MD & Douglas Cooper, PhD \\
\hline Michelle Peterson, DPT, NCS & Angela Drake, $\mathrm{PhD}$ \\
\hline Micaela Cornis-Pop, PhD, SLP & Charles Engel, MD, MPH, COL, USA, MC \\
\hline Patricia A. Rikli, PhD, MSN, BSN & Lori Simmers Geckle USACHPPM \\
\hline Robert L. Ruff, MD, PhD & Kathy Helmick, MS, CNRN, CRNP \\
\hline Steven G. Scott, DO & Charles Hoge, MD, COL, USA, MC \\
\hline Barbara J. Sigford, MD, PhD & Michael Jaffee, MD, COL, FS, USAF \\
\hline Kristin A. Silva, RNC, MN, NP & Robert Labutta, MD, COL, USA, MC \\
\hline Kathryn Tortorice, Pharm D, BCPS & Geoffrey Ling, MD, PhD, COL, USA, MC \\
\hline Rodney D. Vanderploeg, PhD, ABPP-CN & Lynne Lowe, PT, DPT, OCS, LTC \\
\hline \multirow[t]{3}{*}{ Warren Withlock, MD } & Sheryl Mims, RN \\
\hline & David T. Orman, MD, DAC COL \\
\hline & Benjamin E. Solomon, MD LTC, USA, MC \\
\hline PRIVATE SECTOR & Jay M. Stone, PhD Lt Col, USAF \\
\hline Jeffrey Barth PhD, ABPP-CN & Kimialeesha Thomas, RN, MSN \\
\hline \multirow[t]{2}{*}{ Kathleen R. Bell, MD } & Mary Tolbert, PA-C \\
\hline & Christopher S. Williams, MD, COL, USAF \\
\hline $\begin{array}{l}\text { OFFICE OF QUALITY AND } \\
\text { PERFORMANCE }\end{array}$ & $\begin{array}{l}\text { QUALITY MANAGEMENT DIVISION } \\
\text { US ARMY MEDICAL COMMAND }\end{array}$ \\
\hline Joseph Francis, MD, MPH & Angela Klar, RN, MSN, ANP-CS \\
\hline Carla Cassidy, RN, MSN, NP & Ernest Degenhardt, RN, MSN, ANP-FNP, COL, AN \\
\hline \multicolumn{2}{|r|}{$\begin{array}{l}\text { FACILITATOR: } \\
\text { Oded Susskind, MPH }\end{array}$} \\
\hline $\begin{array}{l}\text { RESEARCH: } \\
\text { Jessica Cohen, M.S., M.P.H. } \\
\text { Jennifer J. Kasten, Ph.D. } \\
\text { Sue Radcliff } \\
\text { William E. Schlenger, Ph.D. }\end{array}$ & $\begin{array}{l}\text { HEALTHCARE QUALITY INFORMATICS, INC. } \\
\text { Martha D'Erasmo, MPH } \\
\text { Rosalie Fishman, RN, MSN, CPHQ } \\
\text { Joanne Marko, MS, SLP }\end{array}$ \\
\hline
\end{tabular}




\section{Goals of this Guideline}

- To promote evidence-based management of patients diagnosed with mild traumatic brain injury (mTBI)

- To promote efficient and effective assessment of patient's complaints

- To identify the critical decision points in management of patients with concussion/mTBI

- To improve local management of patients with concussion/mTBI and thereby improve patient outcomes

- To promote evidence-based management of individuals with (post-deployment) health concerns related to head injury, blast, or concussion

- To accommodate local policies or procedures, such as those regarding referrals to, or consultation with, specialists

- To motivate administrators at each of the Federal agencies and care access sites to develop innovative plans to break down barriers that may prevent patients from having prompt access to appropriate care

- To diagnose concussion/mTBI accurately and in a timely manner

- To appropriately assess and identify those patients who present with symptoms following a concussion/mTBI or other consequences of head injury

- To identify those patients who may benefit from further assessment, brief intervention and/or ongoing treatment

- To improve the quality and continuum of care for patients with concussion/mTBI

- To identify those patients who may benefit from early intervention and treatment to prevent future complications from concussion/mTBI

- To improve health related outcomes for patients with concussion/mTBI

- To reduce morbidity and mortality from concussion/mTBI.

\section{Document Presentation:}

- The Guideline is organized around three separate Algorithms:

o Algorithm A: Initial Presentation

o Algorithm B: Management of Symptoms

o Algorithm C: Follow-up of Persistent Symptoms

- Annotations and recommendations in the text match the Box numbers and Letters in the respective algorithms.

- There are a limited number of recommendations that are based on best evidence literature. Therefore, in annotations for which there are evidence based studies to support the recommendations the Strength of Recommendation [SR] based on the level of evidence is presented in brackets for these recommendations. Recommendations that are not based on evidence were derived by consensus of experts. No SR is presented for these recommendations. 


\section{Evidence Rating}

\begin{tabular}{|c|c|}
\hline A & $\begin{array}{c}\text { A strong recommendation that the clinicians provide the intervention to eligible } \\
\text { patients. } \\
\text { Good evidence was found that the intervention improves important health } \\
\text { outcomes and concludes that benefits substantially outweigh harm. }\end{array}$ \\
\hline B & $\begin{array}{r}\text { A recommendation that clinicians provide (the service) to eligible patients. } \\
\text { At least fair evidence was found that the intervention improves health } \\
\text { outcomes and concludes that benefits outweigh harm. }\end{array}$ \\
\hline C & $\begin{array}{r}\text { No recommendation for or against the routine provision of the intervention is made. } \\
\text { At least fair evidence was found that the intervention can improve health } \\
\text { outcomes, but concludes that the balance of benefits and harms is too close } \\
\text { to justify a general recommendation. }\end{array}$ \\
\hline D & $\begin{array}{l}\text { Recommendation is made against routinely providing the intervention to } \\
\text { asymptomatic patients. } \\
\text { At least fair evidence was found that the intervention is ineffective or that } \\
\text { harms outweigh benefits. }\end{array}$ \\
\hline I & $\begin{array}{l}\text { The conclusion is that the evidence is insufficient to recommend for or against } \\
\text { routinely providing the intervention. } \\
\text { Evidence that the intervention is effective is lacking, or poor quality, or } \\
\text { conflicting, and the balance of benefits and harms cannot be determined. }\end{array}$ \\
\hline
\end{tabular}

\section{Conventions used in this Guideline:}

The terms concussion and $m T B I$ are used interchangeably. The use of the term concussion or history of mild TBI may be preferred when communicating with the patient, indicating a transient condition, avoiding the use of the terms "brain damage" or "brain injury" that may inadvertently reinforce misperceptions of symptoms or insecurities about recovery. The term concussion/mTBI will be used throughout this document as a convention.

Two terms commonly used in the literature, Post Concussive Syndrome (PCS) and Post Concussion Disorder (PCD), also have the potential to reinforce illness behavior and the constellations of symptoms are not accurately described as either a syndrome or disorder. The term Persistent Post-Concussive Symptoms (PPCS) will be used throughout this document as a convention when referring to symptoms related to mTBI that do not remit despite initial treatment. 


\section{GUIDELINE KEY POINTS}

\section{General}

- The management of patients who present with symptoms following a concussion/mTBI injury should focus on promoting recovery and avoiding harm

- A patient-centered approach should be used to provide the needed reassurance and motivation, since patients with prolonged symptoms are suffering, distressed, and in need of guidance, education, support, and understanding

- Currently, there are no universal standard criteria for the definition of concussion/mTBI and the diagnosis is based primarily on the characteristics of the immediate sequelae following the event

- Concussion/mTBI is a common injury, with a time-limited and predictable course. The majority of patients with concussion/mTBI do not require any specific medical treatment

- Experience in contemporary military operations suggests that substantial short-term and long-term neurologic deficits (similar to those following concussion/mTBI) can be caused by blast exposure without a direct blow to the head and may manifested in isolation or part of polytrauma.

\section{Natural Course of disease}

- The vast majority of patients who have sustained a concussion/mTBI improve with no lasting clinical sequelae

- Patients should be reassured and encouraged that the condition is transient and full recovery is expected. The term 'brain damage' should be avoided. A risk communication approach should be applied

- The vast majority of patients recover within hours to days, with a small proportion taking longer. In an even smaller minority, symptoms may persist beyond six months to a year

- $\quad$ The symptoms associated with Post-Concussion Syndrome (PCS) are not unique to mTBI. The symptoms occur frequently in day to day life among healthy individuals and are also found often in persons with other conditions such as chronic pain or depression.

\section{Return to Work /Duty Activity}

- Patients sustaining a concussion/mTBI should return to normal (work/duty/school/leisure) activity post-injury as soon as possible

- A gradual resumption of activity is recommended

- If physical, cognitive, or behavioral complaints/symptoms re-emerge after returning to previous normal activity levels, a monitored progressive return to normal activity as tolerated should be recommended.

\section{Early intervention}

- Early education of patients and their families is the best available treatment for concussion/mTBI and for preventing/reducing the development of persistent symptoms 
- A primary care model can be appropriate for the management of Concussion/mTBI when implemented by an interdisciplinary team with special expertise.

\section{Symptom Management}

- Treatment of somatic complaints (e.g. sleep, dizziness/coordination problems, nausea, numbness, smell/taste, vision, hearing, fatigue, appetite problems) should be based upon individual factors and symptom presentation

- Headache is the single most common symptom associated with concussion/mTBI and assessment and management of headaches in individuals should parallel those for other causes of headache

- Medication for ameliorating the neurocognitive effects attributed to concussion/mTBI is not recommended

- Medications for headaches, musculoskeletal pain, or depression/anxiety must be carefully prescribed to avoid the sedating properties, which can have an impact upon a person's attention, cognition, and motor performance

- Treatment of psychiatric symptoms following concussion/mTBI should be based upon individual factors and the nature and severity of symptom presentation, and may include both psychotherapeutic and pharmacological treatment modalities

- In patients with persistent post-concussive symptoms (PPCS), which have been refractory to treatment, consideration should be given to other factors including psychiatric, psychosocial support, and compensatory/litigation. 


\section{Table of Contents}

\section{By Topics}

Page

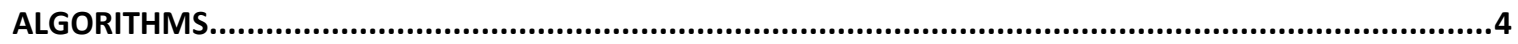

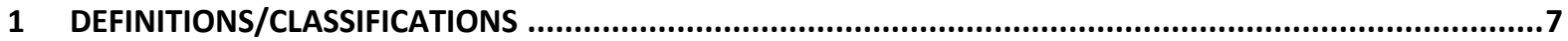

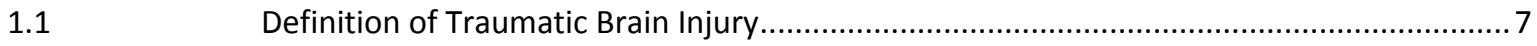

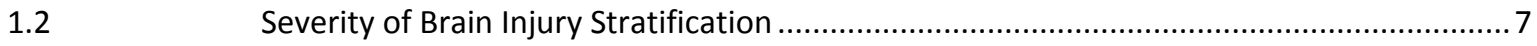

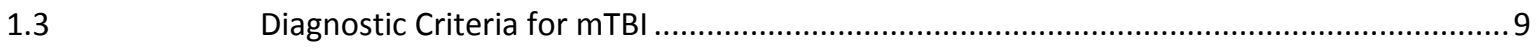

$1.4 \quad$ Symptoms Associated with Concussion/mTBI ........................................................

$1.5 \quad$ Post Deployment Delayed Awareness and Delayed Reporting of Symptoms ..................10

$1.6 \quad$ Persistent Symptoms after Concussion/mTBI ....................................................... 12

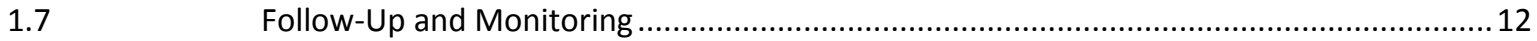

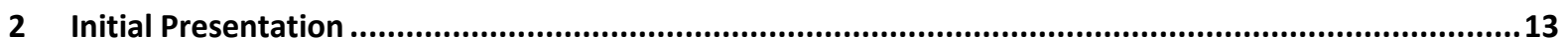

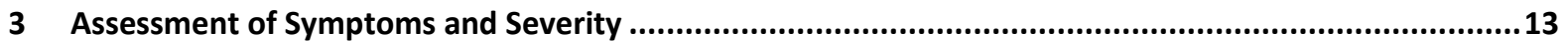

3.1 History, Physical Examination, Laboratory Tests, Imaging ........................................13

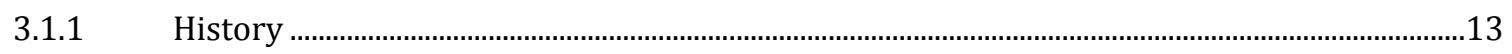

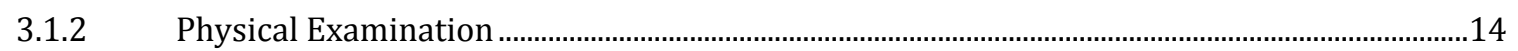

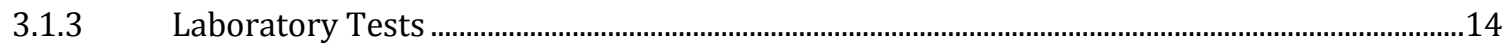

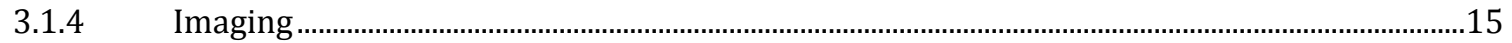

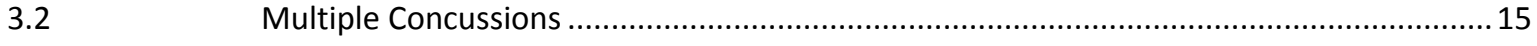

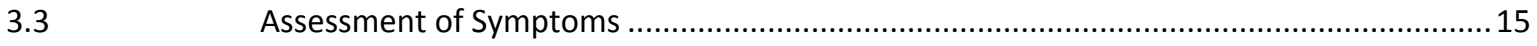

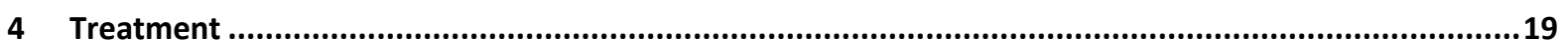

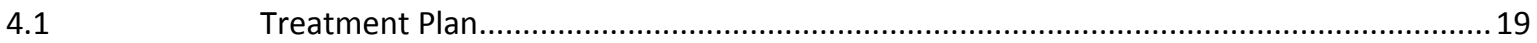

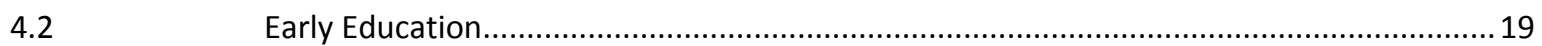

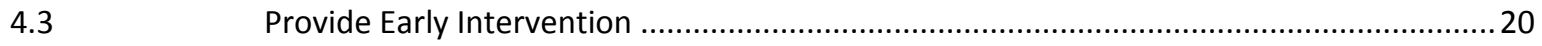

Return to Activity (Duty/Work/School/Leisure) ....................................................20

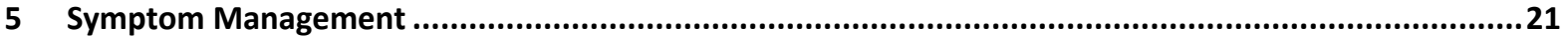

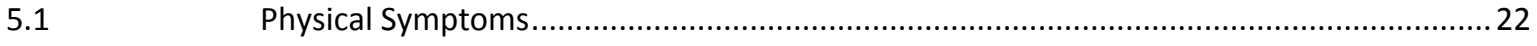

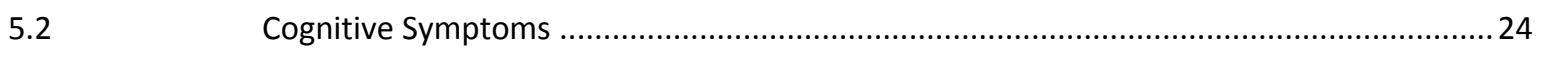

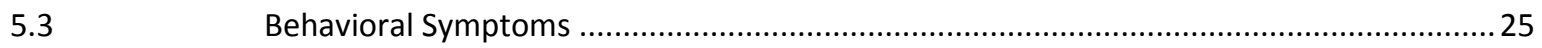

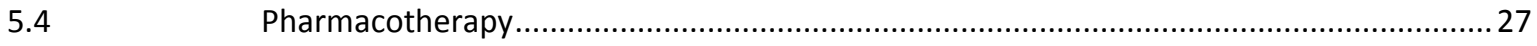

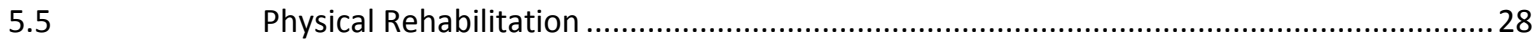

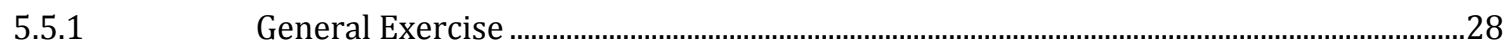

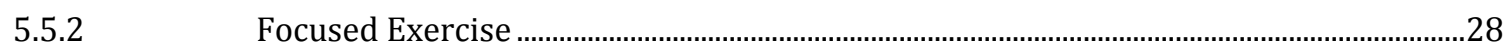

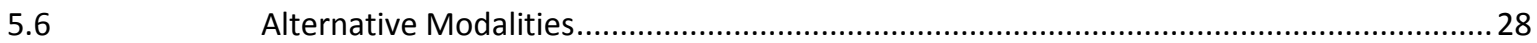

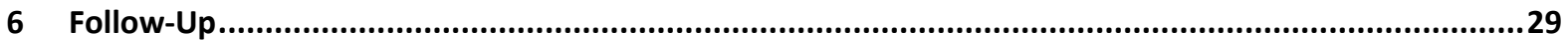

7 Assessment of Persistent Symptoms ..............................................................................30

Risk Factors for Persistent Post-Concussive Symptoms .................................................... 


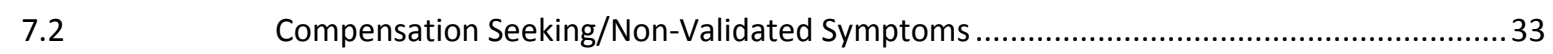

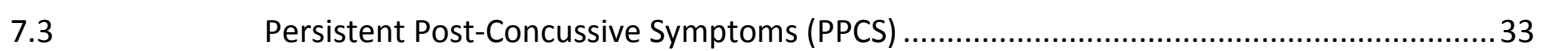

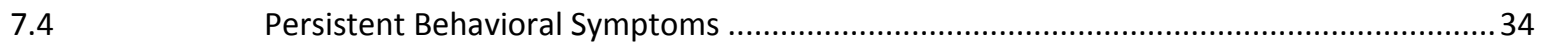

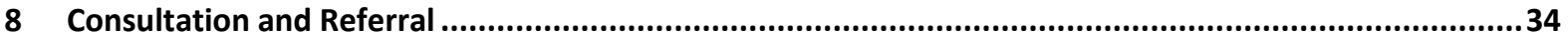

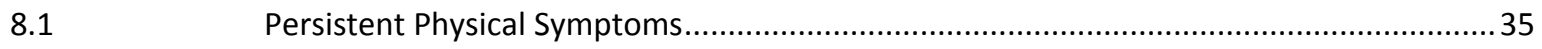

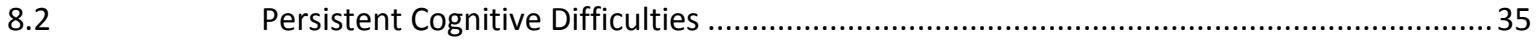

9 Rehabilitation of Patients with Persistent Post-Concussive Symptoms (PPCS).................................37

9.1 Case Management in the Care of Patients with mTBI ..................................................37

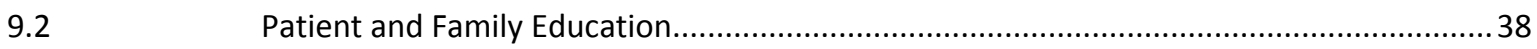

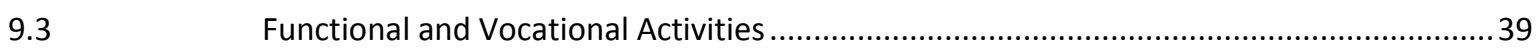

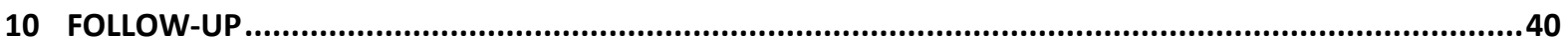

\section{APPENDIX D: Treatment of Physical Symptoms}

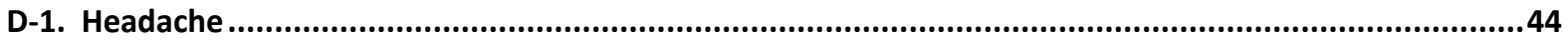

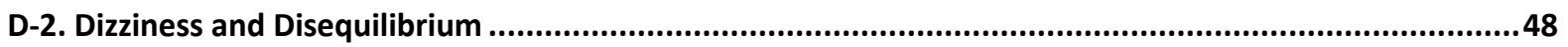

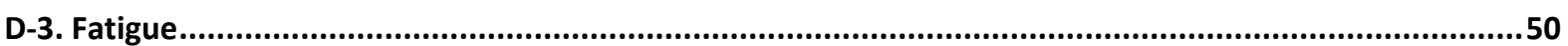

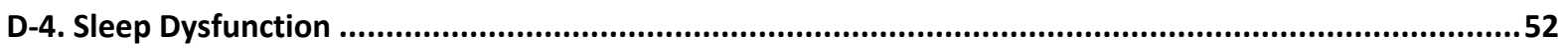

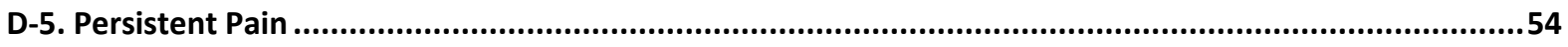

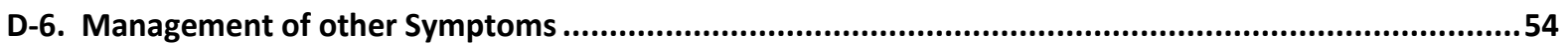

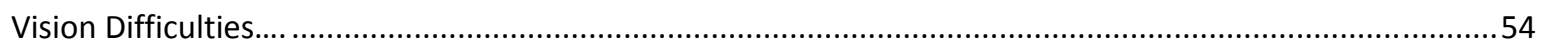

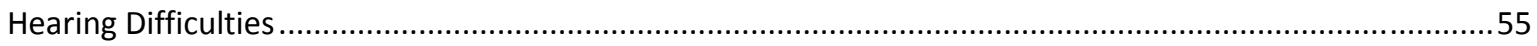

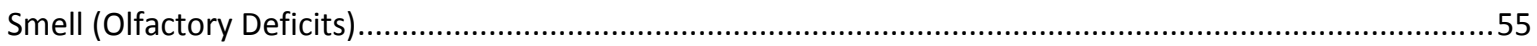

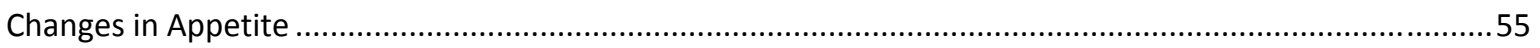

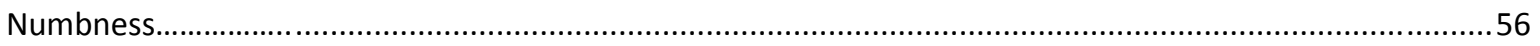

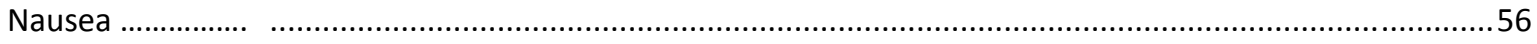

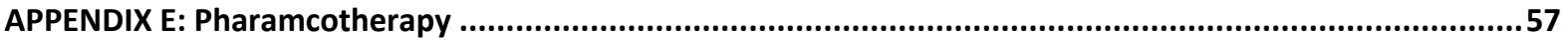

APPENDIX G: Acronym List ............................................................................................60 


\section{Algorithms and Annotations}

\section{Table of Contents}

Algorithms

A: Initial Presentation

Annotation A-1 Person Injured with Head Trauma Resulting in Possible Alteration/Loss of Consciousness.. 7

Annotation A-2 Urgent/emergent conditions identified? ............................................................... 8

Annotation A-3 Evaluate for Diagnosis of Concussion/mTBI, Based on History ......................................... 9

Annotation A-4 Are Concussion/mTBI with Related Symptoms Present?................................................. 9

Annotation A-5 Management of $m$ TBI in combat or ongoing military operation (deployment) .................10

Annotation A-6 Management of acute mTBI in non-deployed or civilian patients ..................................10

Annotation A-7 Is person currently on treatment for mTBI symptoms? ................................................. 12

Annotation A-8 Provide Education and Access Information; Follow-Up as Indicated ................................12

B: Management of Concussion/mTBI Symptoms ............................................................................

Annotation B-1 Person Diagnosed with Concussion/mTBI .............................................................. 13

Annotation B-2 Complete a History, Physical Examination; Minimal Mental Examination and Psychosocial Evaluation ............................................................................... 13

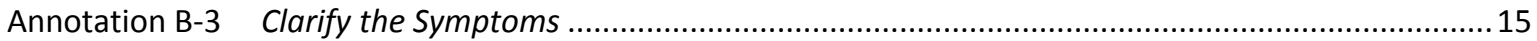

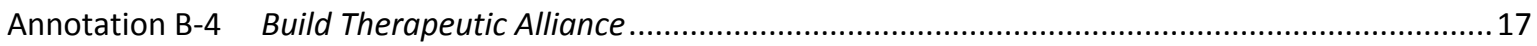

Annotation B-5 Determine Treatment Plan .................................................................................... 19

Annotation B-6 Educate Patient/Family on Symptoms and Expected Recovery of Concussion/mTBI..........19

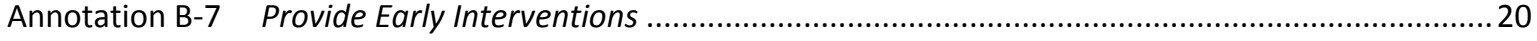

Annotation B-8 Initiate Symptom-Based Treatment Modalities .............................................................21

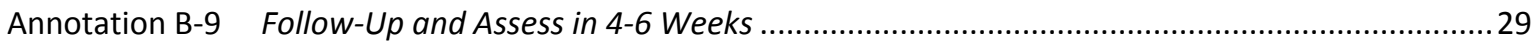

C: Follow-Up Management of Persistent Concussion/mTBI Symptoms ..................................................30

Annotation C-1 Person Diagnosed with Concussion/mTBI and Persistent Symptoms Beyond 4-6 Weeks Follow-Up............................................................................. 30

Annotation C-2 Reassess Symptom Severity and Functional Status Complete Psychosocial Evaluation......30

Annotation C-3 Assess for Possible Alternative Causes for Persistent Symptoms ...................................32

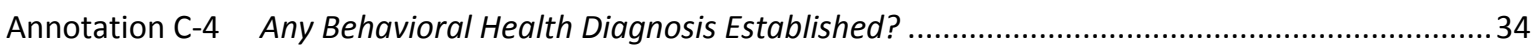

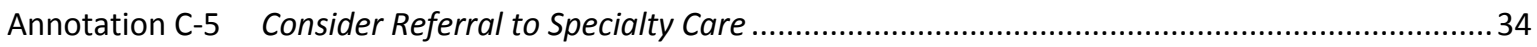

Annotation C-6 Any Persistent Symptoms (Physical, Cognitive or Emotional)? .......................................35

Annotation C-7 Consider Referral to Occupational or Vocational Therapy and Community Integration Programs (Continue Case Management) ................................................................... 37

Annotation C- 8 Follow-Up and Reassess in 3-4 Months................................................................ 40

APPENDICES: ...................................................................................................................41

Appendix B: Structured Interview for Collecting Head Trauma Event Characteristics ............................42

Appendix D Treatment of Physical Symptoms ..........................................................................44

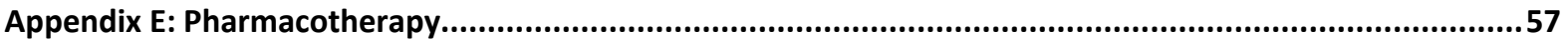

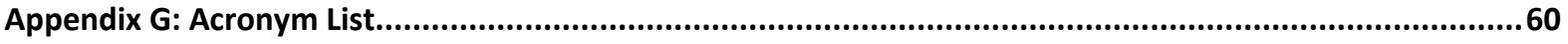




\section{VA/DoD Clinical Practice Guideline for \\ Management of Concussion/mild-Traumatic Brain Injury \\ A: Initial Presentation}

Person injured with head trauma resulting in alteration or loss of consciousness (possible mTBI)

(See sidebar 1 )

$$
\text { [A-1] }
$$

2

4

Evaluate for diagnosis of
concussion/mild-TBI based on history

(See sidebar 3)

[A-3]

5 Is the diagnosis moderate or severe $\mathrm{TBI}$ ?
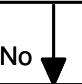

7

Are concussion/mTBI with related symptoms present?

(See sidebar 4) [ A-4 ]

Provide education and access information

Screen for:

- Stress disorders

- Substance use disorders

- Mental health conditions

Follow-up as indicated [A-8]

\section{Sidebar 1 - Possible Causes for Head Trauma}

- Blast or explosion

- Head striking or being struck by object, or fall

- Undergoing acceleration/deceleration movement (e.g., Motor vehicle accident) [A-1]

\begin{tabular}{|c|c|}
\hline \multicolumn{2}{|c|}{ Sidebar2 - Indicators for Immediate Referra } \\
\hline 1. Current altered & 7. Worsening headache \\
\hline consciousness & 8. Cannot recognize people \\
\hline 2. Progressively declining & or disoriented to place \\
\hline neurological exam & 9. Behaves unusually or \\
\hline 3. Pupillary asymmetry & confused and irritable \\
\hline 4. Seizures & 10. Slurred speech \\
\hline 5. Repeated vomiting & 11. Unsteady on feet \\
\hline 6. Double vision & $\begin{array}{l}\text { 12. Weakness or numbness } \\
\text { in arms/legs }\end{array}$ \\
\hline
\end{tabular}

Sidebar 3 - Diagnostic Criteria for Concussion/mild TBI

- Loss of or a decreased level of consciousness for less than 30 minutes

- Loss of memory for events immediately up to a one day after the injury

- Alteration of consciousness/mental state for 0-24 hours after the injury

- Normal structural imaging

- Glascow Coma Score: 13-15 (best value within first 24 hours if available) [A-3 ]

Exit algorithm
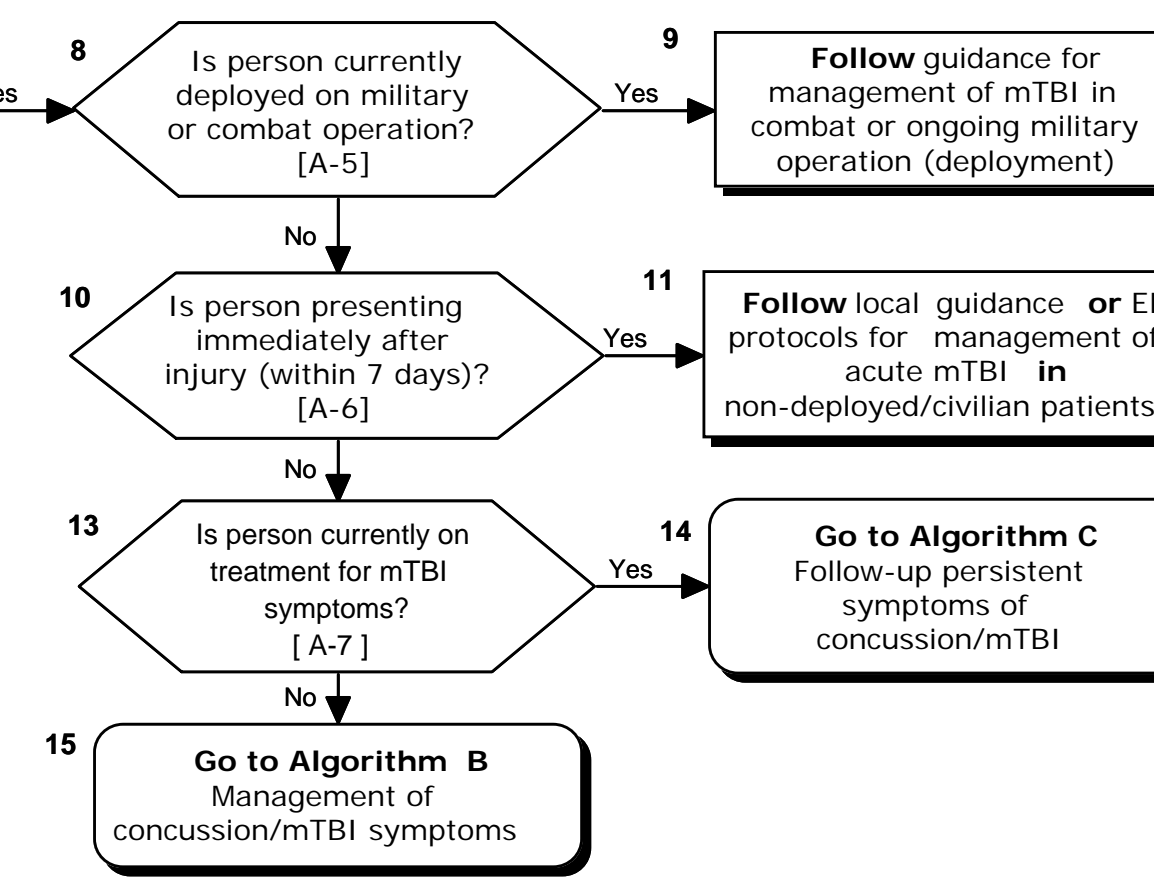

Follow local guidance or ED protocols for management of acute $\mathrm{MTBI}$ in non-deployed/civilian patients
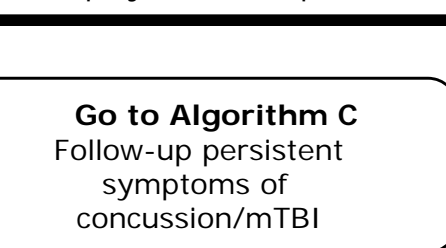

\section{SIdebar 4 - Post-Concussion/mTBI Related Symptoms *}

Physical Symptoms :

Headache, dizziness, balance disorders, nausea, fatigue, sleep disturbance, blurred vision, sensitivity to light, hearing difficulties/loss, sensitivity to noise, seizure, transient neurological abnormalities, numbness tingling
Cognitive Symptoms :

Attention, concentration, memory, speed of processing, judgment, executive control.
Behavior/Emotional Symptoms : Depression, anxiety, agitation, irritability, impulsivity, aggression.

* Symptoms that develop within 30 days post injury 


\section{Management of Concussion/mild-Traumatic Brain Injury \\ B: Management of Symptoms}

1

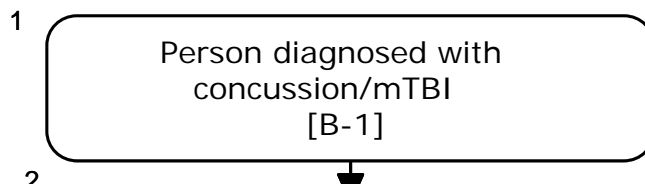

2

Complete history and physical

examination, lab tests, MSE and psychosocial evaluation

[B-2]

3

Clarify the symptoms

[See sidebar 5]

[B-3]

Build therapeutic alliance

[B-4]

4

Evaluate and treat co-occurring disorders or diseases (such as mood, anxiety, stress or substance use disorders )

5

Determine treatment plan

[B-5]

6

Educate patient/family on

symptoms and expected recovery

(See sidebar 6)

[B-6]

7

Provide early interventions

[B-7] (See sidebar 6)
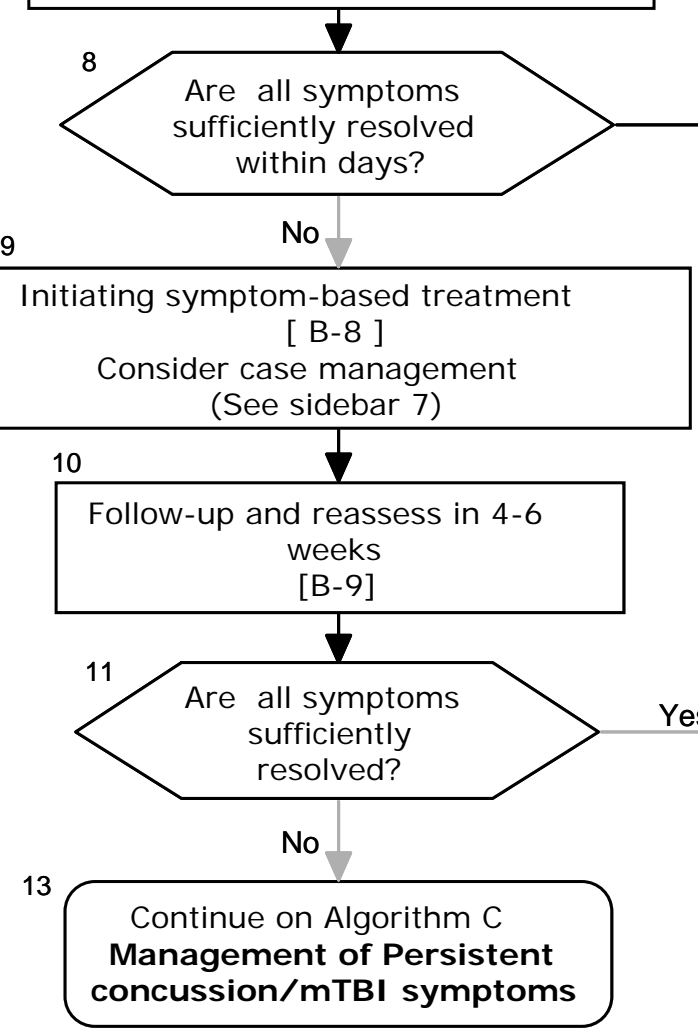

\section{Sidebar 5: Symptom Attributes}

Duration of symptom

Onset and triggers

Location

Previous episodes

Intensity and impact

Previous treatment and response

Patient perception of symptom

I mpact on functioning

[ B-3 ]

\section{Sidebar 6: Early I ntervention}

- Provide information and education on symptoms and recovery

- Educate about prevention of further injuries

- Reassure on positive recovery expectation

- Empower patient for self management [ B-6 ]

- Provide sleep hygiene education

- Teach relaxation techniques

- Recommend limiting use of caffeine/tobacco/alcohol

- Recommend graded exercise with close monitoring

Encourage monitored progressive return to normal duty/work/activity

[ B-7 ]

\section{Sidebar 7: Case Management}

Assign case manager to:

- Follow-up and coordinate (remind) future appointments

- Reinforce early interventions and education

- Address psychosocial issues (financial, family, housing or school/work)

- Connect to available resources
Follow-up as needed

Encourage \& reinforce

Monitor for comorbid conditions Address:

- Return to work/duty/activity

- Community participation

- Family/social issues 


\section{VA/DoD Clinical Practice Guideline for Management of Concussion/mild-Traumatic Brain Injury C: Follow-up Persistent Symptoms}

Person diagnosed with concussion/mtbi and persistent symptoms beyond 4- 6 weeks not responding to initial treatment [C-1]

2

Reassess symptoms severity and
functional status
Complete psychosocial evaluation (See sidebar 8) [C-2]

Sidebar 8 - Psychosocial Evaluation

1. Support system

2. Mental health history

3. Co-occurring conditions (chronic pain, mood disorders, stress disorder, personality disorder)

4. Substance use disorder

5. Secondary gain issues (Compensation, litigation)

6. Unemployment or change in job status

7

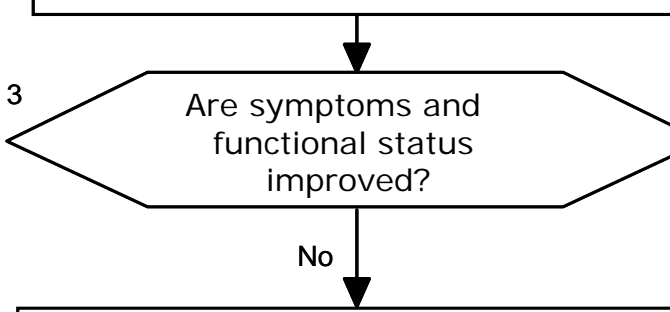

Assess for possible alternative causes for persistent symptoms; Consider behavioral component (e.g., sleep or a mood disorder) [ C-3 ]
4

Yes

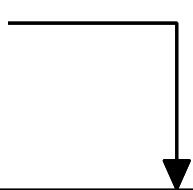

I nitiate/continue

symptomatic treatment

Provide patient and family education

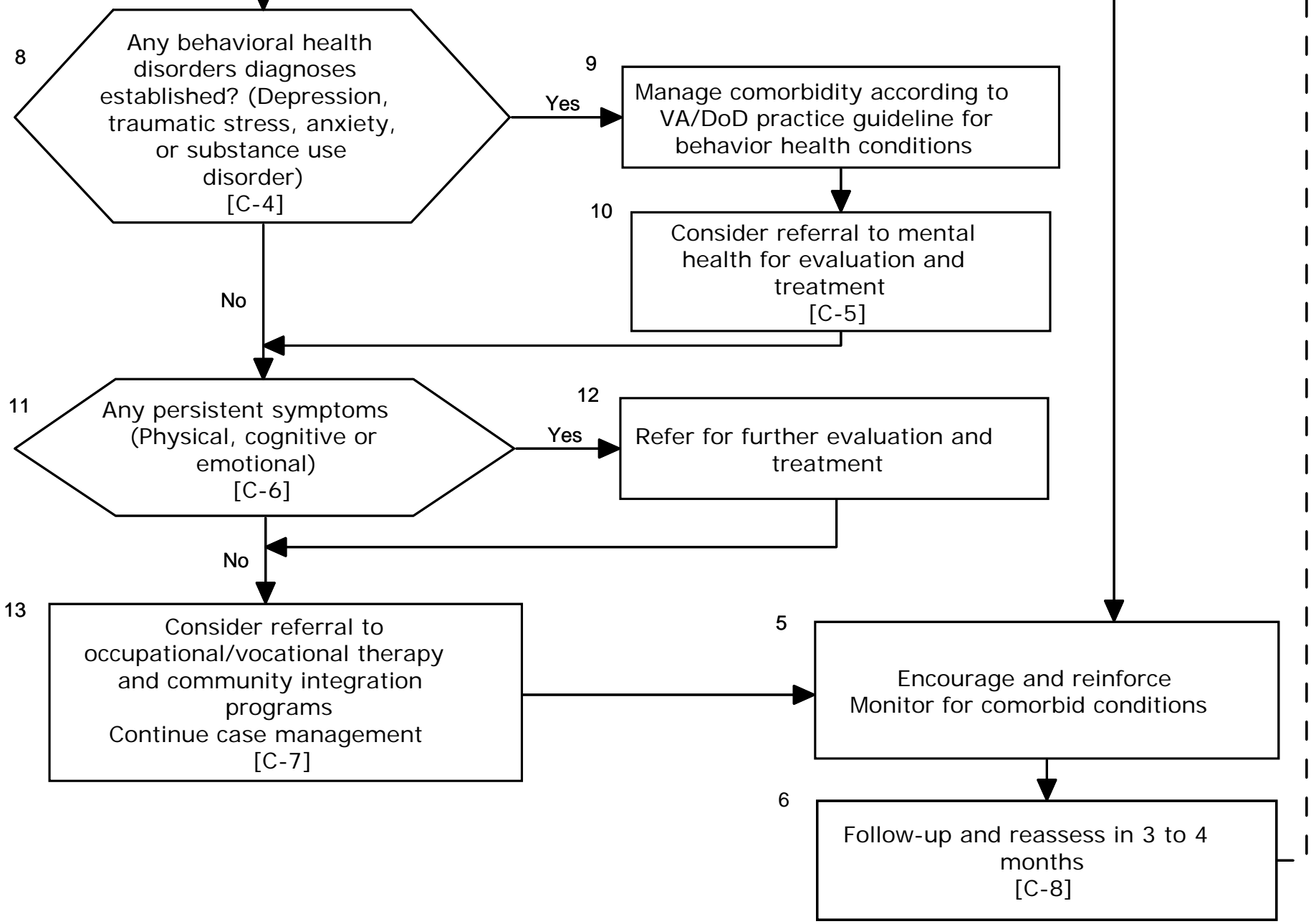




\title{
A: Initial Presentation
}

\author{
Annotation A-1 Person Injured with Head Trauma Resulting in Possible Alteration or Loss of Consciousness
}

\section{DEFINITIONS/CLASSIFICATIONS}

\subsection{Definition of Traumatic Brain Injury}

A traumatically induced structural injury and/or physiological disruption of brain function as a result of an external force that is indicated by new onset or worsening of at least one of the following clinical signs, immediately following the event:

- Any period of loss of or a decreased level of consciousness (LOC)

- Any loss of memory for events immediately before or after the injury (post-traumatic amnesia [PTA])

- Any alteration in mental state at the time of the injury (confusion, disorientation, slowed thinking, etc.) (Alteration of consciousness/mental state [AOC])

- Neurological deficits (weakness, loss of balance, change in vision, praxis, paresis/plegia, sensory loss, aphasia, etc.) that may or may not be transient

- Intracranial lesion.

External forces may include any of the following events: the head being struck by an object, the head striking an object, the brain undergoing an acceleration/deceleration movement without direct external trauma to the head, a foreign body penetrating the brain, forces generated from events such as a blast or explosion, or other forces yet to be defined.

The above criteria define the event of a TBI. Not all individuals exposed to an external force will sustain a TBI, but any person who has a history of such an event with immediate manifestation of any of the above signs and symptoms can be said to have had a TBI.

\subsection{Severity of Brain Injury Stratification}

TBI is further categorized as to severity into mild, moderate, or severe based on the length of LOC, AOC, or PTA (see Table A- 1 Classification of TBI Severity). Acute injury severity is determined at the time of the injury.

- The patient is classified as mild/moderate/severe if s/he meets any of the criteria in Table A-1 within a particular severity level. If a patient meets criteria in more than one category of severity, the higher severity level is assigned.

- If it is not clinically possible to determine the brain injury level of severity because of medical complications (e.g., medically induced coma), other severity markers are required to make a determination of the severity of the brain injury.

- Abnormal structural imaging (e.g., Magnetic Resonance Imaging or Computed Tomography Scanning) attributed to the injury will result in the individual being considered clinically to have greater than mild injury.

In addition to traditional imaging studies, other imaging techniques such as functional magnetic resonance imaging, diffusion tensor imaging, positron emission tomography scanning; electrophysiological testing such as electroencephalography; and neuropsychological or other standardized testing of function have been used in the evaluation of persons with TBIs, but are not considered in the currently accepted criteria for measuring severity at the time of the acute injury outlined in Table A -1. 
The severity level has prognostic value, but does not necessarily predict the patient's ultimate level of functioning. There is substantial evidence that the epidemiology, pathophysiology, natural history, and prognosis for concussion/mTBI are different than for moderate and severe TBI. For example, moderate and severe TBI are often associated with objective evidence of brain injury on brain scan or neurological examination (e.g., neurological deficits) and objective deficits on neuropsychological testing, whereas these evaluations are frequently not definitive in persons with concussion/mTBI. The natural history and prognosis of moderate and severe TBI are much more directly related to the nature and severity of the injury in moderate and severe TBI, whereas factors unrelated to the injury (such as co-existing mental disorders) have been shown to be the strong predictors of symptom persistence after a concussion/mTBI.

\section{Table A- 1 Classification of TBI Severity}

\begin{tabular}{|l|l|l|l|}
\hline Criteria & Mild & Moderate & Severe \\
\hline Structural imaging & Normal & Normal or abnormal & Normal or abnormal \\
\hline Loss of Consciousness (LOC) & $0-30 \mathrm{~min}$ & $>30$ min and $<24$ hours & $>24 \mathrm{hrs}$ \\
\hline $\begin{array}{l}\text { Alteration of } \\
\text { consciousness/mental state } \\
\text { (AOC) }\end{array}$ & $\begin{array}{l}\text { a moment up to } \\
24 \text { hrs }\end{array}$ & \multicolumn{2}{|l|}{$>$} \\
\hline Post-traumatic amnesia (PTA) & $0-1$ day & $>1$ and $<7$ days & $>7$ days \\
\hline $\begin{array}{l}\text { Glascow Coma Scale (best } \\
\text { available score in first 24 } \\
\text { hours) }\end{array}$ & $13-15$ & $9-12$ & $<9$ \\
\hline
\end{tabular}

* Alteration of mental status must be immediately related to the trauma to the head. Typical symptoms would be: looking and feeling dazed and uncertain of what is happening, confusion, difficulty thinking clearly or responding appropriately to mental status questions, and being unable to describe events immediately before or after the trauma event.

\section{Concussion}

The terms concussion and $m T B I$ can be used interchangeably. The use of the term concussion or history of mild TBI may be preferred when communicating with the patient, indicating a transient condition, avoiding the use of the terms "brain damage" or "brain injury" that may inadvertently reinforce misperceptions of symptoms or insecurities about recovery. The patient who is told $\mathrm{s} /$ he has "brain damage" based on vague symptoms complaints and no clear indication of significant head trauma may develop a long-term perception of disability that is difficult to undo.

The term concussion/mTBI will be used throughout this document as a convention.

Annotation A-2 Urgent/emergent conditions identified?

\section{RECOMMENDATIONS}

1. The following physical findings, signs and symptoms ("Red Flags") may indicate an acute neurologic condition that requires urgent specialty consultation (neurology, neuro-surgical) :

a. Altered consciousness

b. Progressively declining neurological examination

c. Pupillary asymmetry

d. Seizures

e. Repeated vomiting

f. Double vision

g. Worsening headache 
h. Cannot recognize people or is disoriented to place

i. Behaves unusually or seems confused and irritable

j. Slurred speech

k. Unsteady on feet

1. Weakness or numbness in arms / legs

Annotation A-3 Evaluate for Diagnosis of Concussion/mTBI, Based on History

\subsection{Diagnostic Criteria for mTBI}

\section{BACKGROUND}

In the U.S., the most widely accepted criteria for mild TBI are those proposed by the American College of Rehabilitation Medicine (ACRM, 1993). They are "a physiological disruption of brain function as a result of a traumatic event as manifested by at least one of the following: alteration of mental state, loss of consciousness (LOC), loss of memory or focal neurological deficit, that may or may not be transient; but where the severity of the injury does not exceed the following: post-traumatic amnesia (PTA) for greater than 24 hours, after the first 30 minutes Glasgow Coma Score (GCS) 13 15 , and loss of consciousness is less than 30 minutes." There are other criteria used by other medical groups. However, most agree that common criteria include GCS score of 13-15, brief LOC, brief PTA and negative head computed tomography (CT) scan.

\section{RECOMMENDATIONS}

1. A diagnosis of mTBI should be made when there is an injury to the head as a result of blunt trauma, acceleration or deceleration forces or exposure to blast that result in one or more of the following conditions:

a. Any period of observed or self-reported:

- Transient confusion, disorientation, or impaired consciousness

- Dysfunction of memory immediately before or after the time of injury

- Loss of consciousness (LOC) lasting less than 30 minutes.

b. Observed signs of neurological or neuropsychological dysfunction, such as:

- Headache, dizziness, irritability, fatigue or poor concentration, when identified soon after injury, can be used to support the diagnosis of mild TBI, but cannot be used to make the diagnosis in the absence of loss of consciousness or altered consciousness.

2. The severity of TBI must be defined by the acute injury characteristics and not by the severity of symptoms at random points after trauma.

Annotation A-4 Are Concussion/mTBI with Related Symptoms Present?

\subsection{Symptoms Associated with Concussion/mTBI}

Concussion/mTBI is associated with a variety of symptoms that will manifest immediately following the event, and may resolve quickly, within minutes to hours after the injury event, or they may persist longer. The most typical signs and symptoms after concussion fall into one or more of the following three categories:

a. Physical: headache, nausea, vomiting, dizziness, fatigue, blurred vision, sleep disturbance, sensitivity to light/noise, balance problems, transient neurological abnormalities 
b. Cognitive: attention, concentration, memory, speed of processing, judgment, executive function

c. Behavioral/emotional: depression, anxiety, agitation, irritability, impulsivity, aggression.

Signs and symptoms may occur alone or in varying combinations and may result in functional impairment.

Although a variety of symptoms can occur in association with TBI, they are not part of the definition of TBI, and there are no pathognomonic symptoms or signs. The term "mild TBI" refers only to the initial injury severity and should not be interpreted referring to the level of the severity of the symptoms.

Signs and symptoms, following the concussion, should not be attributed to concussion/mTBI if they are better explained by pre-existing conditions or other medical, neurological, or psychological causes except in cases of an immediate exacerbation of a pre-existing condition.

Symptoms associated with concussion/mTBI are not unique. These symptoms occur frequently in dayto-day life among healthy individuals and are often found in persons with other conditions such as chronic pain, depression or other traumatic injuries. These symptoms are also common to any number of pre-existing/pre-morbid conditions the patient may have had.

Annotation A-5 Is Person Currently Deployed on Combat or Ongoing Military Operation?

RECOMMENDATIONS

1. Management of service members presenting for care immediately after a head injury (within 7 days) during military combat or ongoing operation should follow guidelines for acute management published by DoD. (See: Recommendations for acute management of concussion/mTBI in the deployed setting, Defense and Veterans Brain Injury Center Consensus August, 2008)

(This guidance is not included in this evidence-based guideline.)

Annotation A-6 $\quad$ Is Person Presenting Immediately (Within 7 Days) After Injury? (Non-Military/Civilian Setting)

RECOMMENDATIONS

1. Management of non-deployed service members, veterans, or civilian patients presenting for care immediately after a head injury (within 7 days) should follow guidelines for acute management. (See Recommendations for acute management in guideline published by the American College of Emergency Medicine and the Center for Disease Control and Prevention (ACEP/CDC, 2008)

(These protocols and guidance are not included in this evidence-based guideline.)

\subsection{Post Deployment Delayed Awareness and Delayed Reporting of Symptoms}

\section{BACKGROUND}

The elapsed time since the exposure to the head injury (trauma) and the self-reporting of symptoms by the patient to their primary care provider may vary. This period is very important in assessing the risk of developing concussion/mTBI symptoms and determining the appropriate intervention.

The concussion/mTBI algorithms are designed to accommodate patients entering the healthcare system at different intervals post-injury. Algorithm A (Initial Presentation) describes a new entry into the healthcare system and is not dependent on the time since injury. It does not follow the traditional acute, sub-acute, and post-acute phases of brain injury. This is particularly important with combat- 
related TBI that may inherently lead to delays in seeking treatment due to discounting or misattributing symptoms, and reluctance to report health problems. The initial management of symptoms related to concussion/mTBI is then described in Algorithm B (Management of Symptoms). Algorithm C (Follow-up Persistent Symptoms) will apply to any service person/veteran for whom treatment of concussion symptoms previously had been started.

\subsubsection{Initial Stages following mTBI/Concussion}

Example: Individual sustains a head injury and presents to a provider two weeks following the injury. The provider uses Algorithm A to diagnose concussion/mTBI, and Algorithm B to initiate the management of symptoms. If the symptoms do not remit within 4 to 6 weeks of the initial treatment, the provider follows Algorithm C to manage the persistent symptoms.

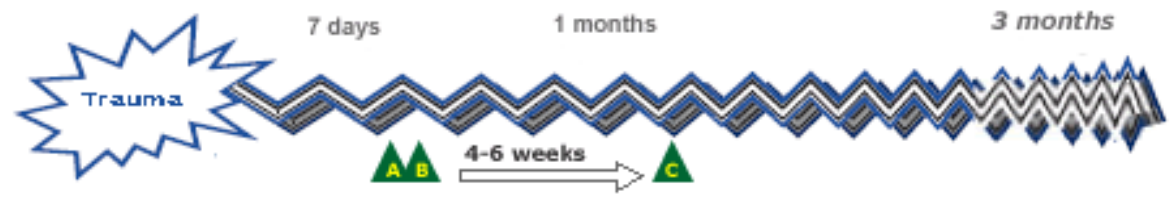

Figure 1. Initial Stages following mTBI/Concussion

\subsubsection{Delayed Initial Presentation of Symptoms}

Example: Individual sustains a head injury followed by experiencing symptoms. The patient does not access medical care for weeks or months post-injury. Despite the long elapsed time since injury, the provider uses Algorithm A and B for the initial work-up to make the diagnosis and initiate treatment. This initial treatment may be provided in a setting designated for diagnosis and management of mTBI. If the symptoms do not remit within 4 to 6 weeks of the initial treatment, the provider follows Algorithm C to manage the persistent symptoms.

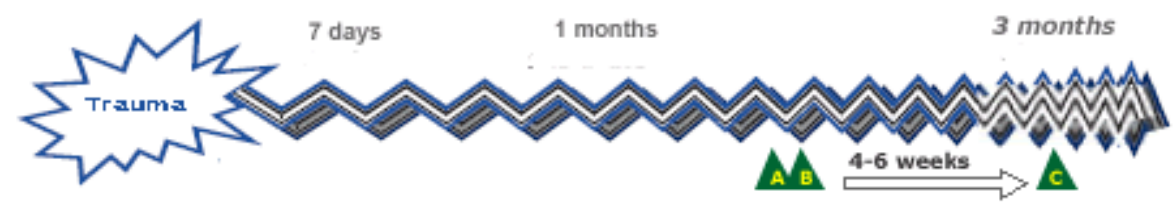

Figure 2 Delayed Initial Presentation of Symptoms

\section{RECOMMENDATIONS}

1. Service members or veterans identified by post deployment screening or who present with symptoms should be assessed and diagnosed according to Algorithm A - Initial Presentation. The initial evaluation and management will then follow the recommendations in Algorithm $\boldsymbol{B}$ Management of Symptoms.

2. Patients who continue to complain of concussion/mTBI-related symptoms beyond 4 to 6 weeks after treatment has been initiated, should have the assessment for these chronic symptoms repeated and should be managed using Algorithm C - Follow-up Persistent Symptoms.

3. Patients who continue to have persistent symptoms beyond 2 years post-injury despite treatment (Algorithm C) do not require repeated assessment for these chronic symptoms and should be conservatively managed using a simple symptom-based approach.

4. Patients with symptoms that develop more than 30 days after a concussion should have a focused diagnostic work-up specific to those symptoms only. These symptoms are highly unlikely to be the result of the concussion and therefore the work-up and management should not focus on the initial concussion. 
Annotation A-7 Is Person Currently on Treatment for mTBI Symptoms?

\subsection{Persistent Symptoms after Concussion/mTBI}

\section{BACKGROUND}

Most symptoms and signs that occur in the acute period following a single concussion resolve quickly (within hours or days) after the injury. There is debate about the incidence of developing persistent symptoms after concussion, largely due to the lack of an accepted case definition for persistent symptoms and the fact that none of the symptoms are specific to concussion. There is no consensus on a case definition for persistent symptoms attributed to concussion/mTBI and no consensus on the time course when acute symptoms should be considered persistent. As a result, the important focus should be on treating the symptoms rather than on determining the etiology of the symptoms.

\section{RECOMMENDATIONS}

1. Persons who complain about somatic, cognitive or behavioral difficulties after concussion/mTBI should be assessed and treated symptomatically regardless of the elapsed time from injury.

2. The assessment of an individual with persistent concussion/mTBI related symptoms should be directed to the specific nature of the symptoms regardless of their etiology.

3. The management of an individual who has sustained a documented concussion/mTBI and has persistent physical, cognitive and behavioral symptoms after one month should not differ based on the specific underlying etiology of their symptoms (i.e., concussion vs. pain, concussion vs. stress disorder).

4. In communication with patients and the public, this guideline recommends using the term concussion or history of mild-TBI and to refrain from using the term 'brain damage'.

Annotation A-8 Provide Education and Access Information; Follow-Up as Indicated

\subsection{Follow-Up and Monitoring}

It is important to closely monitor the injured person for concussion/mTBI related symptoms and provide supportive education over the initial 30 days. Individuals who sustain a concussion/mTBI and are asymptomatic can be reassured and advised about precautionary measures to prevent future head injury.

RECOMMENDATIONS

1. Individuals who sustain a concussion/mTBI and are asymptomatic should be reassured about recovery and advised about precautionary measures to prevent future head injury.

2. Patients should be provided with written contact information and be advised to contact their healthcare provider for follow-up if their condition deteriorates or they develop symptoms.

3. Individuals who sustain a concussion/mTBI and are asymptomatic should be screened for comorbid mental health disorders (MDD, PTSD, and SUD) and dangerousness. 


\title{
B: Management of Concussion/mTBI Symptoms
}

\author{
Annotation B-1 Person Diagnosed with Concussion/mTBI
}

\section{Initial Presentation}

The vast majority of individuals with concussion/mTBI will have no difficulties or complaints lasting more than a couple of weeks following the injury.

Although, early interventions have been shown to prevent symptoms, some persons sustaining a concussion/mTBI during deployment will not receive early diagnosis or will not seek treatment, and therefore their symptoms will be addressed only after a temporal delay. This guideline recommends that these individuals will be first treated following the algorithm and annotations in Algorithms A and B. If treatment has already been rendered for concussion/mTBI related symptoms and despite treatment the patient continues to experience symptoms, the management will follow the recommendations in Algorithm C.

Patients managed in Algorithm B are service persons or veterans identified by post deployment screening, or who present to care with symptoms or complaints related to head injury.

Patients presenting for care immediately after head injury (within 7 days) should follow guidelines for acute management and should not use this algorithm. (See Annotation A-5 and A-6)

Annotation B-2 Complete a History, Physical Examination; Minimal Mental Examination and Psychosocial Evaluation

\section{Assessment of Symptoms and Severity}

\subsection{History, Physical Examination, Laboratory Tests, Imaging}

\section{BACKGROUND}

Although the initial part of the screening process for mild TBI depends on self-report, the second-level assessment relies on obtaining a careful detailed medical history, physical examination, and a psychosocial assessment. The goal of the assessment is to evaluate the symptoms in order to optimize care, to improve outcomes, and ultimately reduce disability following a concussion/mTBI. It is recognized that patients may not present for medical care immediately following concussion/mTBI. Therefore, the purpose of the assessment may vary slightly based on the timing of the presentation following injury. For patients presenting immediately after the injury event, assessment will include the necessity to rule out neurosurgical emergencies. In patients who present with delayed injury-to assessment intervals, the assessment will include confirmation linking the symptoms to the concussive event. Regardless of the time that has elapsed since injury, management should begin with the patient's first presentation for treatment.

\subsubsection{History}

Taking an accurate history is an essential part of the diagnostic work-up. The first and most critical step in the evaluation of persons with possible concussion symptoms should clearly characterize the initial injury and determine whether the symptoms are temporally related to the event characterized as a concussion/mTBI.

\section{RECOMMENDATIONS}

1. Individuals who are presumed to have symptoms related to concussion/mTBI or who are identified as positive for mTBI on the initial screening should receive specific assessment of their symptoms.

2. Medical history should include the following:

a. Obtaining detailed information on the patient's symptoms and health concerns.

b. Obtaining detailed information of the injury event including mechanism of injury, duration and severity of alteration of consciousness, immediate symptoms, symptom course and prior treatment 
c. Screening for pre-morbid conditions, potential co-occurring conditions or other psychosocial risk factors, such as substance use disorders that may exacerbate or maintain current symptom presentation (using standardized screening tools such as, PHQ-2, Audit-C, PTSD screen)

d. Evaluating signs and symptoms indicating potential for neurosurgical emergencies that require immediate referrals

e. Assessing of danger to self or others.

3. Patient's experiences should be validated by allowing adequate time for building a provider-patient alliance and applying a risk communication approach.

(See Appendix B: Structured Interview for Collecting Head Trauma Event Characteristics)

\subsubsection{Physical Examination}

\section{RECOMMENDATIONS}

1. The physical examination of the person sustaining a concussion/mTBI should focus on the following:

a. A focused neurologic examination, including a Mental Status Examination (MSE), cranial nerve testing, extremity tone testing, deep tendon reflexes, strength, sensation, and postural stability (Romberg's Test, dynamic standing)

b. A focused vision examination including gross acuity, eye movement, binocular function and visual fields/attention testing

c. A focused musculoskeletal examination of the head and neck, including range of motion of the neck and jaw, and focal tenderness and referred pain.

2. The following physical findings, signs and symptoms ("Red Flags") may indicate an acute neurologic condition that requires urgent specialty consultation (neurology, neuro-surgical) :
a. Altered consciousness
b. Progressively declining neurological examination
c. Pupillary asymmetry
d. Seizures
e. Repeated vomiting
f. Double vision
g. Worsening headache
h. Cannot recognize people or is disoriented to place
i. Behaves unusually or seems confused and irritable
j. Slurred speech
k. Unsteady on feet
1. Weakness or numbness in arms/legs.

\subsubsection{Laboratory Tests}

\section{BACKGROUND}

Because diagnostic and cognitive tests have limited ability to predict long-term outcomes for persons with concussion/mTBI, investigators are focused on searching for biochemical markers that may be useful in diagnosis and prognosis.

\section{RECOMMENDATIONS}

1. Laboratory testing is not necessary to confirm or manage symptoms associated with concussion/mTBI.

2. Laboratory testing may be considered for evaluating other non-TBI causes of the symptoms presented.

3. There is insufficient evidence to support the use of serum biomarkers for concussion/mTBI in clinical practice. $[\mathrm{SR}=\mathrm{I}]$ 


\subsubsection{Imaging}

\section{BACKGROUND}

The role of neuroimaging in diagnosing concussion/mTBI continues to evolve and be debated in the literature. Various neuroimaging modalities can be employed in helping to identify structural neuropathology. Structural imaging modalities include Computed Tomography (CT) Scan, Magnetic Resonance Imaging (MRI) Diffusion Tensor Imaging (DTI). Functional imaging modalities include Single Photon Emission Computed Tomography (SPECT), Positron Emission Tomography (PET) and functional MRI (fMRI). However, many of these modalities are still at the preliminary/research stage of development. Currently, CT scan is the modality of choice as a diagnostic tool for acute concussion $/ \mathrm{mTBI}$. The absence of abnormal findings on CT does not preclude the presence of concussion/mTBI.

\section{RECOMMENDATIONS}

1. A patient who presents with any signs or symptoms that may indicate an acute neurologic condition that requires urgent intervention should be referred for evaluation that may include neuroimaging studies.

2. Neuroimaging is not recommended in patients who sustained a concussion/mTBI beyond the emergency phase (72 hours post-injury) except if the condition deteriorates or red flags are noted.

\subsection{Multiple Concussions}

\section{BACKGROUND}

Some patients presenting for an initial evaluation may report a history of repeated concussions that have worsened their symptoms. The approach of symptom-based assessment and treatment of repeated concussion should be similar to the management of exposure to a single injury.

\section{RECOMMENDATIONS}

1. The management of a patient who has sustained multiple concussions should be similar to the management for a single concussion/mTBI. [SR $=\mathrm{I}]$

2. The patient with multiple concussions and his/her family should be educated to create a positive expectation of recovery. [SR $=\mathrm{I}]$

\section{Annotation B-3 Clarify the Symptoms}

\subsection{Assessment of Symptoms}

\section{BACKGROUND}

Patients who have sustained a concussion/mTBI may complain about post-injury symptoms that can be grouped into three categories: physical, cognitive, and emotional/behavioral. (See Annotation A-4) The clinical presentation is expected to include at least some elements of the classic constellation of postconcussive symptoms and gradual, although sometimes incomplete, symptomatic improvement over time.

Although post-concussive symptoms (PCS) are most often discussed in the context of mTBI, these terms and their clinical referents are not synonymous with mTBI: mTBI describes a type of injury whereas the post-concussion symptoms describe a set of problems presumably resulting from the injury.

It is particularly important to define clearly the patient's symptoms, as well as the course and resolution (or lack thereof) of those symptoms since the time of injury. Documenting frequency and severity of symptoms is important to set a baseline for monitoring subsequent treatment efficacy or establishment of co-occurring conditions. (See Table B-1)

Patients should be asked about the impact of their symptoms on their daily function. Individuals with a concussion/mTBI are typically independent in basic activities of daily living (ADLs) (e.g., grooming, bathing, dressing, toileting, and mobility). However, a small minority of patients may present with problems in areas of instrumental ADLs (IADLs). These abilities may effect independent functioning in tasks such as driving, home management, childcare, financial management, and performance at work. 
Patients with symptoms should be asked open-ended questions to allow them to describe their difficulties. Presenting patients with symptom checklists is not recommended, however, these lists may be useful in documenting symptoms and symptom intensity.

\section{Patient Perception of Symptoms}

Patients should be given the opportunity to relate their experiences and complaints at each visit in their own way. As the patient relates the history, important nonverbal clues are often provided. The clinician should observe the patient's attitude, reactions, and gestures while being questioned, as well as his or her choice of words or emphasis. The impact from the symptoms may range from annoying to totally disabling and patient perceptions regarding the cause and impact are important to understand in managing the disorder. Stressors such as occupational and family issues should also be explored.

\section{RECOMMENDATIONS}

1. Self-reported symptomatology is an appropriate assessment of the patient's condition in concussion/mTBI when the history is consistent with having sustained an injury event and having a subsequent alteration in consciousness. [SR $=\mathrm{C}]$

2. Assessment of the patient with concussion/mTBI should include detailed questioning about the frequency, intensity and nature of symptoms the patient experiences, and their impact on the patient's social and occupational functioning.

3. Assessment should include a review of all prescribed medications and over-the-counter supplements for possible causative or exacerbating influences. These should include caffeine, tobacco and other stimulants, such as energy drinks.

4. The patient who sustained a concussion/mTBI should be assessed for sleep patterns and sleep hygiene.

5. If the patient's symptoms significantly impact daily activities (such as child care, safe driving), a referral to rehabilitation specialists for a functional evaluation and treatment should be considered. 


\section{Clarify the Symptoms}

Questions that may prompt patients to provide important attributes of their symptoms are summarized in the following table.

Table B-1. Clarification of Symptoms

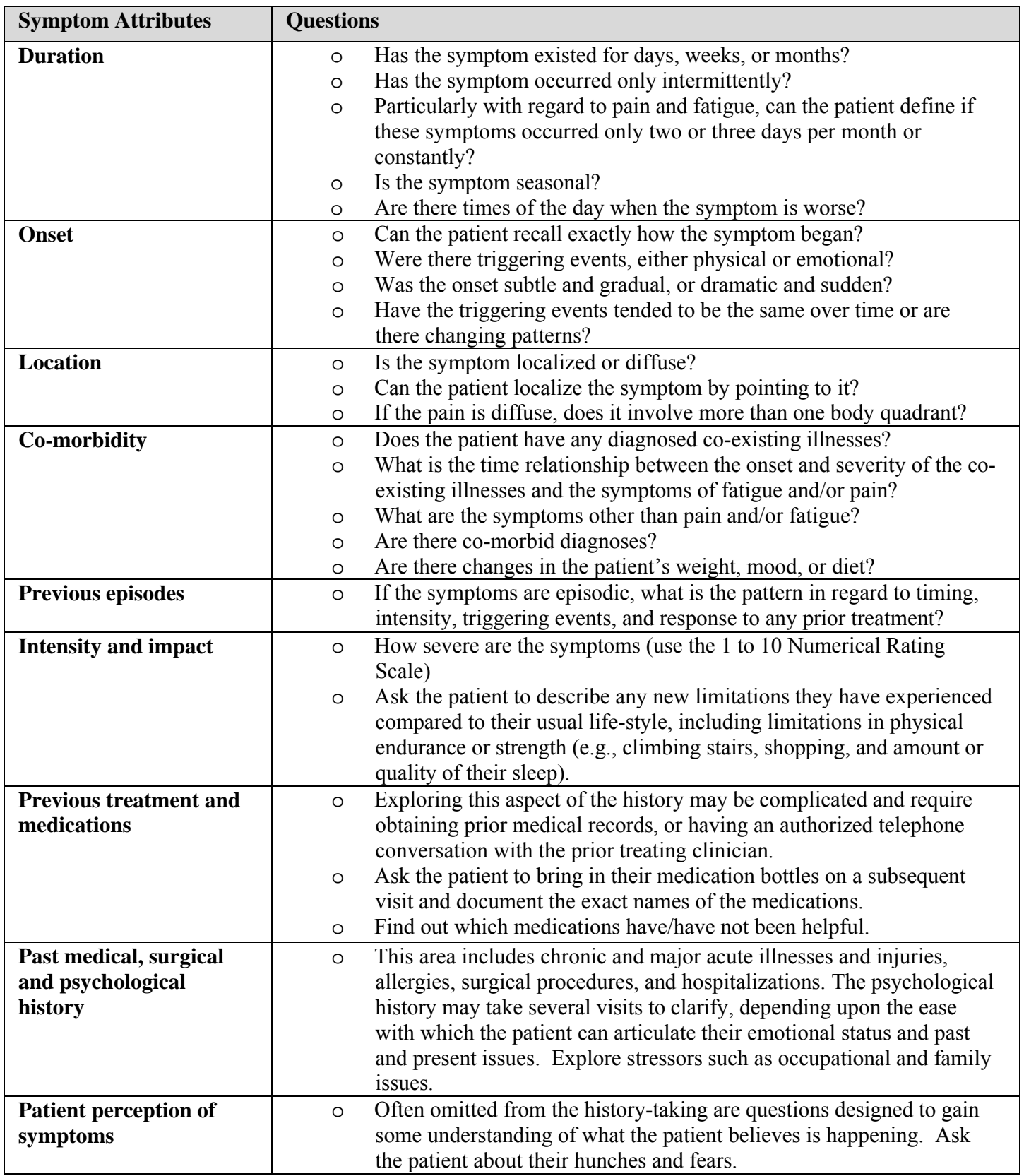

Annotation B-4 Build Therapeutic Alliance

Interactions with patients/ families that involve real or suspected mTBI may be highly emotional, with reactions ranging from disbelief to anger to frustration to relief. Some patients will present with diagnosable symptoms, while others may believe they're suffering from mTBI when subsequent medical 
assessments may indicate otherwise. In both situations, medical staffs face the difficult challenge of effectively communicating the diagnosis, treatment, and prognosis for recovery to patients/ families, while minimizing and/or avoiding undue anxiety.

The information provided by medical personnel to individuals who have experienced a concussion/mTBI can either amplify and increase their symptoms and distress (iatrogenic factors), or can minimize and normalize their symptoms and reduce distress.

The lack of a definitive diagnosis or single effective treatment can make the management of patients with concussion/mTBI symptoms challenging and may also cause frustration for both the patient and the provider. To counter this, a high level of patient trust and faith in the clinician is required in order to maintain continuity of care and continue patient management through regular follow-up appointments. A therapeutic alliance between the patient and clinician should be established during the initial evaluation.

Risk communication approaches include:

1. Caring and empathy, including perceived sincerity, ability to listen, and to see issues from the perspective of others. Of the four factors, patient perceptions of caring and empathy are the most important.

2. Competence and expertise, including perceived intelligence, training, experience, education level, professional attainment, knowledge, and command of information. These are the easiest factors to establish because health care providers are automatically perceived by the public to be credible sources of information.

3. Dedication and commitment, including perceived altruism, diligence, self-identification, involvement, and hard work. Perceptions of dedication and commitment are influenced by patient perceptions of the health care provider's hard work in the pursuit of health goals.

4. Honesty and openness, including perceived truthfulness, candidness, fairness, objectivity, and sincerity. Perceptions of this factor result from both nonverbal cues (i.e., posture, eye contact, facial expressions, interruptions, indirect language) and language that conveys sincerity and concern. Sensitivity to nonverbal cues is especially invaluable in ultimately understanding and communicating effectively with the patient and their family.

Useful strategies to strengthen the partnership with the patient:

- Acknowledge and indicate commitment to understand the patient's concerns and symptoms

- Encourage an open and honest transfer of information that will provide a more comprehensive picture of the patient's concerns and medical history

- Present information regarding a positive outcome and symptom remission to create an expectation of recovery

- Indicate commitment to allocate sufficient time and resources to resolving the patient's concerns

- Avoid open skepticism or disapproving comments in discussing the patient's concerns

- At each patient visit, the clinician should consider the following:

- Ask if there are unaddressed or unresolved concerns

- Summarize and explain all test results

- Schedule follow-up visits in a timely manner

- Explain that outstanding or interim consultations will be reviewed during the follow-up visits

- Offer to include the concerned family member or significant other in the follow-up visit. 
Annotation B-5 Determine Treatment Plan

\section{Treatment}

\subsection{Treatment Plan}

\section{BACKGROUND}

After the screening, assessment, and diagnosis of concussion $/ \mathrm{mTBI}$ are completed decisions are made about treatment. Treatment for patients with concussion/mTBI focuses on symptom management and education of patient and family. Education should emphasize recovery, gradual resumption of work and social responsibilities, and teaching compensatory strategies and environmental modifications. Most patients with symptoms following a single concussion/mTBI of recent onset can be successfully managed in the primary care setting without the need for specialty intervention.

Patients should be encouraged to implement changes in life-style including exercise, diet, sleep hygiene, stress reduction, relaxation training, scheduling leisure activities and pacing to improve treatment outcomes.

\section{RECOMMENDATIONS}

1. Develop and document a summary of the patient's problems.

2. Develop a potential treatment plan that includes severity and urgency for treatment interventions.

3. Discuss with the patient the general concept of concussion sequelae, treatment options and associated risk/benefits and prognosis of illness to determine the patient's preferences.

4. Emphasizing good prognosis and empowering the patient for self-management.

5. Implement the treatment plan and follow up.

6. Referral to specialty care is not required in the majority of patients with concussion/mTBI, if their symptoms resolve in the early post acute recovery period as expected.

7. Treatment should be coordinated and may include consultation with rehabilitation therapists, pharmacy, collaborative mental health, and social support.

\subsection{Early Education}

\section{BACKGROUND}

Education provided to patients and their support system about the nature and common manifestations of concussion/mTBI is a critical aspect of intervention. Communication of health information from providers helps manage patient expectations and can prevent the development of concussion/mTBI symptoms and/or reduce their duration, number, and severity. It is generally recommended that the initial educational intervention occur at the time of establishing the concussion/mTBI diagnosis. Follow-up education should take place at intervals and in a format that is appropriate to the treatment and services provided. Additionally, the patient's learning needs, reading skills, vision or hearing difficulties, cultural and religious beliefs, and emotional or cognitive limitations should be taken into consideration when delivering educational information.

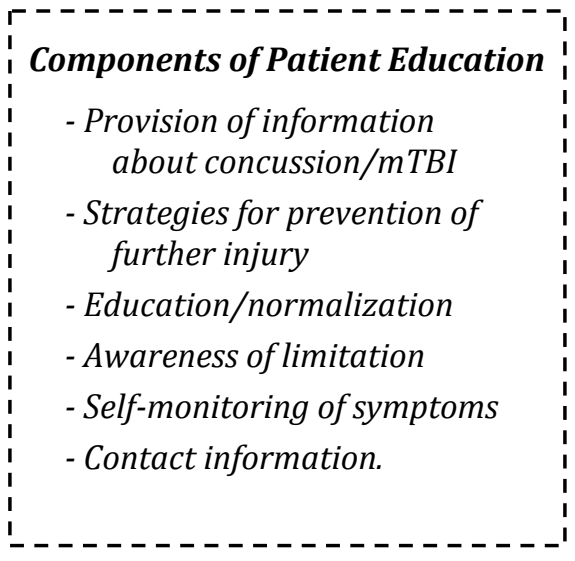

\section{RECOMMENDATIONS}

1. Patients who sustain a concussion/mTBI should be provided with information and education about concussion/mTBI symptoms and recovery patterns as soon as possible after the injury. Education should be provided in printed material combined with verbal review and consist of:

a. Symptoms and expected outcome. $[\mathrm{SR}=\mathrm{A}]$ 
b. Normalizing symptoms (education that current symptoms are expected and common after injury event). $[\mathrm{SR}=\mathrm{A}]$

c. Reassurance about expected positive recovery. $[\mathrm{SR}=\mathrm{A}]$

d. Techniques to manage stress (e.g., sleep education, relaxation techniques; minimize consumption of alcohol, caffeine and other stimulants). [SR $=\mathrm{B}$ ]

2. Information and education should also be offered to the patient's family, friends, employers, and/or significant others.

3. Symptomatic management should include tailored education about the specific signs and symptoms that the patient presents and the recommended treatment.

4. Patients should be provided with written contact information and be advised to contact their healthcare provider for follow-up if their condition deteriorates or if symptoms persist for more than 4-6 weeks. $[\mathrm{SR}=\mathrm{B}]$

\subsection{Provide Early Intervention}

\section{BACKGROUND}

Concussion/mTBI can significantly impact some patients' physical, mental and social well-being. Treatment should address these three main areas. Initial interventions expected to improve physical wellbeing include education, improved sleep habits, a graduated exercise regimen (monitored through physical therapy, exercise trainers, and social supports), and medication (monitored by a clinician). Mental wellbeing may be improved through stress relief and relaxation, medication, and creating a supportive social network. Social well-being may be improved through resolving legal, financial, occupational, or recreational problems.

\section{RECOMMENDATIONS}

1. Provide early intervention maximizing the use of non-pharmacological therapies:

a. Review sleep patterns and hygiene and provide sleep education including education about excess use of caffeine/tobacco/alcohol and other stimulants

b. Recommend graded aerobic exercise with close monitoring.

\subsection{Return to Activity (Duty/Work/School/Leisure)}

\section{BACKGROUND}

A successful treatment outcome for a patient who has sustained a concussion is the return to duty/work/school or other usual daily activities. Part of the early intervention for concussion/mTBI involves protecting the patient from a secondary insult or further injury by limiting or eliminating their duty status or job requirements until proper recovery is obtained. Although rare, the possibility of second impact syndrome must be prevented by altering a concussed patient's vocational duties when they are high risk for re-injury. Exertional testing prior to the return to work or military duty may help to ensure adequate resolution of symptoms in a high stress state or combat environment.

Return to activity assessment is based on an inventory of symptoms and their severity and the patient's jobspecific tasks. With the exception of those activities and duties that are characterized as high-risk for repeat concussions, all individuals with concussion/mTBI should be encouraged to expediently return to activity at their maximum capacity.

Activity restrictions are an important part of the treatment regimen for patients with concussion $/ \mathrm{mTBI}$. Activity restriction does not imply complete bed rest but rather a restful pattern of activity throughout the day with minimal physical and mental exertion. 
RECOMMENDATIONS

1. Immediately following any concussion/mTBI, individuals who present with post-injury symptoms should have a period of rest to avoid sustaining another concussion and to facilitate a prompt recovery.

2. Individuals with concussion/mTBI should be encouraged to expediently return to normal activity (work, school, duty, leisure) at their maximal capacity.

3. In individuals who report symptoms of fatigue, consideration should be given to a graded return to work/activity.

4. In instances where there is high risk for injury and/or the possibility of duty-specific tasks that cannot be safely or competently completed, an assessment of the symptoms and necessary needs for accommodations should be conducted through a focused interview and examination of the patient.

5. If a person's normal activity involves significant physical activity, exertional testing can be conducted that includes stressing the body.

6. If exertional testing results in a return of symptoms, a monitored progressive return to normal activity as tolerated should be recommended.

7. Individually based work duty restriction should apply if:

- There is a duty specific task that cannot be safely or competently completed based on symptoms

- The work/duty environment cannot be adapted to the patient's symptom-based limitation

- The deficits cannot be accommodated

- Symptoms reoccur.

Annotation B-8 Initiate Symptom-Based Treatment Modalities

\section{Symptom Management}

Concussion/mTBI is associated with a variety of symptoms that will manifest immediately following the event, and may resolve quickly, within minutes to hours after the injury event, or they may persist longer. Signs and symptoms may occur alone or in varying combinations and may result in functional impairment.

The most typical signs and symptoms following concussion include:

a. Physical: headache, nausea, vomiting, dizziness, fatigue, blurred vision, sleep disturbance, sensitivity to light/noise, balance problems, transient neurological abnormalities

b. Cognitive: attention, concentration, memory, speed of processing, judgment, executive control

c. Behavioral/emotional: depression, anxiety, agitation, irritability, impulsivity, aggression.

There is a complex relationship among concussion/mTBI symptoms (sleep, headache, cognition, and mood) and it is clinically reasonable to expect that that alleviating/improving one symptom may lead to improvement in other symptom clusters. The presence of comorbid psychiatric problems such as a major depressive episode, anxiety disorders (including post-traumatic stress disorder [PTSD]), or substance use disorder (SUD) - whether or not these are regarded as etiologically related to the concussion/mTBI should be treated aggressively using appropriate psychotherapeutic and pharmacologic interventions.

The expected outcome of an intervention should be to improve the identified problem areas, rather than discover a disease etiology or "cure." The persistence of some concussion related symptoms despite the effective treatment for others does not necessarily suggest treatment failure, but may instead indicate the need for additional therapies targeting specific residual symptoms.

The following recommended interventions focus on initial management of the physical, cognitive and behavioral symptoms. Patients with symptoms that persist despite these initial treatment interventions should be managed using Algorithm C: Follow-up Persistent Symptoms 


\subsection{Physical Symptoms}

\section{BACKGROUND}

For purposes of this guideline, physical complaints include headache, pain, sleep disturbances, dizziness, coordination issues, nausea, numbness, smell/taste, vision difficulties (photophobia, phonophobia), hearing difficulties, fatigue, and appetite disturbances. In the majority of cases, these symptoms are markedly improved or have disappeared within 3 months after the injury.

\section{RECOMMENDATIONS}

1. Initial treatment of physical complaints of a patient with concussion/mTBI should be based upon a thorough evaluation, individual factors and symptom presentation.

2. The evaluation should include:

a. Establishing a thorough medical history, completing a physical examination, and review of the medical record (for specific components for each symptoms see Table B-2 Physical Symptoms-Assessment)

b. Minimizing low yield diagnostic testing

c. Identifying treatable causes (conditions) for patient's symptoms

d. Referring for further evaluation as appropriate.

3. The treatment should include:

a. Non-pharmacological interventions such as sleep hygiene education, physical therapy, relaxation and modification of the environment (for specific components for each symptoms see Table B-3 Physical Symptoms-Treatment)

b. Use of medications to relieve pain, enable sleep, relaxation and stress reduction.

4. A consultation or referral to specialists for further assessment should occur when:

a. Symptoms cannot be linked to a concussion event (suspicion of another diagnosis)

b. An atypical symptom pattern or course is present

c. Findings indicate an acute neurologic condition that requires urgent neurologic/neuro-surgical intervention (see Section 3.1.2 - Physical Examination)

d. There are other major co-morbid conditions requiring special evaluation. 
Table B-2. Physical Symptoms - ASSESSMENT

\begin{tabular}{|c|c|c|c|c|c|c|c|c|c|c|}
\hline \multirow{2}{*}{$\begin{array}{c}\text { Common Symptoms } \\
\text { Following } \\
\text { Concussion } / \mathrm{mTBI}^{*}\end{array}$} & \multirow{2}{*}{$\begin{array}{c}\text { Meds } \\
\text { Review }\end{array}$} & \multirow{2}{*}{$\begin{array}{c}\text { Assess } \\
\text { for } \\
\text { HTN }\end{array}$} & \multicolumn{5}{|c|}{ Physical Examination } & \multirow{2}{*}{$\begin{array}{c}\text { Sleep } \\
\text { Review }\end{array}$} & \multirow{2}{*}{$\begin{array}{l}\text { Depression } \\
\text { Screen }\end{array}$} & \multirow{2}{*}{$\begin{array}{l}\text { Differential Diagnoses } \\
\text { Include: }\end{array}$} \\
\hline & & & $\mathbf{G}$ & Neuro & Musc. & Vision & Otological & & & \\
\hline Headaches & $\sqrt{ }$ & $\sqrt{ }$ & & $\sqrt{ }$ & $\sqrt{ }$ & $\sqrt{ }$ & $\sqrt{ }$ & $\sqrt{ }$ & & $\begin{array}{l}\text { Pre-existing headache } \\
\text { disorder } \\
\text { (migraine, tension) } \\
\text { Cervical spine or } \\
\text { musculature } \\
\text { abnormality or pain } \\
\text { CSF leak or pressure } \\
\text { abnormality } \\
\text { Sinus infection } \\
\text { Visual acuity issues (needs } \\
\text { glasses) }\end{array}$ \\
\hline $\begin{array}{l}\text { Feeling dizzy } \\
\text { - Loss of balance } \\
\text { - Poor coordination } \\
\text { - Clumsy }\end{array}$ & $\sqrt{ }$ & & & $\sqrt{ }$ & $\sqrt{ }$ & $\sqrt{ }$ & $\sqrt{ }$ & & & $\begin{array}{l}\text { Inner ear infection } \\
\text { Labyrinthitis } \\
\text { CSF leak or pressure } \\
\quad \text { abnormality } \\
\text { Meniere's disease } \\
\text { Orthostatic hypotension } \\
\text { Central medication effect }\end{array}$ \\
\hline Nausea & $\sqrt{ }$ & & $\sqrt{ }$ & & $\sqrt{ }$ & $\sqrt{ }$ & $\sqrt{ }$ & & & $\begin{array}{l}\text { GI ulcer } \\
\text { GERD } \\
\text { Medication effect }\end{array}$ \\
\hline Change in appetite & $\sqrt{ }$ & & $\sqrt{ }$ & & & & & & & $\begin{array}{l}\text { Nasal polyps } \\
\text { Sinus infection } \\
\text { Traumatic injury to } \\
\quad \text { olfactory or lingual nerves }\end{array}$ \\
\hline $\begin{array}{l}\text { Sleep disturbance } \\
\text { - Difficulty falling or } \\
\text { staying a sleep } \\
\text { (insomnia) }\end{array}$ & $\sqrt{ }$ & & & & & & & $\sqrt{ }$ & $\sqrt{ }$ & $\begin{array}{l}\text { Behavioral health issues } \\
\text { Sleep disorders } \\
\text { Pain }\end{array}$ \\
\hline $\begin{array}{l}\text { Vision problems } \\
\text { - Blurring } \\
\text { - Trouble seeing } \\
\text { - Sensitivity to light }\end{array}$ & $\sqrt{ }$ & & & & $\sqrt{ }$ & $\sqrt{ }$ & $\sqrt{ }$ & $\sqrt{ }$ & & $\begin{array}{l}\text { Retinal detachment } \\
\text { Traumatic injury to lens } \\
\text { Corneal abrasion } \\
\text { Optic nerve damage }\end{array}$ \\
\hline $\begin{array}{l}\text { Hearing difficulty } \\
\text { - Sensitivity to noise }\end{array}$ & $\sqrt{ }$ & & & & & & $\sqrt{ }$ & & & $\begin{array}{l}\text { Inner ear infection } \\
\text { Ear drum inflammation } \\
\text { Ear drum injury } \\
\text { Traumatic auditory nerve } \\
\quad \text { injury }\end{array}$ \\
\hline
\end{tabular}

* Other less common symptoms following concussion/mTBI include:

- Numbness or tingling on parts of the body - Review of medications, neurological exam and EMG to rule out stroke, multiple sclerosis, spinal cord injury, peripheral neuropathy, or thoracic outlet syndrome

- Change in taste and/or smell - neurological exam to rule out nasal polyps, sinus infection, or traumatic injury to olfactory or lingual nerves 
Table B-3. Physical Symptoms - TREATMENT

\begin{tabular}{|c|c|c|}
\hline $\begin{array}{l}\text { Common Symptoms } \\
\text { Following } \\
\text { Concussion/mTBI }\end{array}$ & $\begin{array}{l}\text { Pharmacologic } \\
\text { Treatment }\end{array}$ & $\begin{array}{l}\text { Non-Pharmacologic } \\
\text { Treatment }\end{array}$ \\
\hline Headaches & $\begin{array}{ll}\text { - } & \text { Non narcotic pain meds } \\
\text { - NSAIDs } & \text { - } \\
\text { - Triptans (migraine type) }\end{array}$ & $\begin{array}{l}\text { - Sleep hygiene education } \\
\text { - Physical therapy } \\
\text { - Relaxation }\end{array}$ \\
\hline Feeling dizzy & $\begin{array}{l}\text { - Antibiotics, decongestants for } \\
\text { infections and fluid }\end{array}$ & $-\quad-$ \\
\hline $\begin{array}{l}\text { Loss of balance } \\
\text { Poor coordination } \\
\end{array}$ & 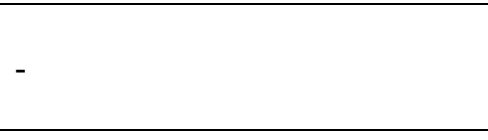 & - Physical therapy \\
\hline Nausea & - Antiemetics & - Sleep hygiene education \\
\hline Change in appetite & - & - \\
\hline \begin{tabular}{|l} 
Sleep disturbances \\
- Difficulty falling or \\
staying asleep \\
(insomnia) \\
\end{tabular} & - Sleep Medications & - Sleep hygiene education \\
\hline \begin{tabular}{|l|} 
Vision problems \\
- Blurring \\
- Trouble seeing \\
- Sensitivity to light \\
\end{tabular} & - & $\begin{array}{l}\text { - Sleep hygiene education } \\
\text { - Light desensitization } \\
\text { - Sunglasses }\end{array}$ \\
\hline $\begin{array}{l}\text { Hearing difficulty } \\
\text { - Sensitivity to noise }\end{array}$ & - & - Environmental Modifications \\
\hline
\end{tabular}

\subsection{Cognitive Symptoms}

\section{BACKGROUND}

Although initial cognitive complaints and problems are common in the first hours and days after a concussion/mTBI, the vast majority of individuals recover within one to four weeks. Early psychoeducational, supportive, and stress management interventions have been shown to increase rate and extent of recovery from somatic, cognitive and behavioral symptoms. As rapid recovery is expected, patients should always be provided with positive expectations.

See Table B-4: Behavioral and Cognitive Symptoms - ASSESSMENT and B-5: Behavioral and Cognitive Symptoms - TREATMENT

\section{RECOMMENDATIONS}

1. All individuals who sustain a concussion/mTBI should be provided with information and education about concussion/mTBI symptoms and recovery patterns as soon as possible after the injury [SR = A] (See Early Education, Section 4.2)

2. A patient sustaining a concussion/mTBI should be evaluated for cognitive difficulties using a focused clinical interview. [SR $=\mathrm{C}]$

3. Comprehensive neuropsychological/cognitive testing is not recommended during the first 30 days post injury. [SR $=\mathrm{D}]$

4. If a pre-injury neurocognitive baseline was established in an individual case, then a post injury comparison may be completed by a psychologist but should be determined using reliable tools and test-retest stability should be ensured. [SR $=\mathrm{B}]$ 


\subsection{Behavioral Symptoms}

\section{BACKGROUND}

Depending upon diagnostic criteria (ICD-9 versus DSM-IV) the following behavioral or personality changes may be considered part of the post-concussion syndrome: irritability, depression, anxiety, emotional lability, fatigue, insomnia, reduced alcohol tolerance, personality changes such as increases in socially inappropriate behaviors, and apathy or lack of spontaneity. Anxiety and depression and other mental health problems also have been associated with concussion/mTBI.

The presence of comorbid psychiatric problems such as a major depressive episode, anxiety disorders (including post-traumatic stress disorder), or substance abuse - whether or not these are regarded as etiologically related to the mild TBI - should be treated aggressively using appropriate psychotherapeutic and pharmacologic interventions.

See Table B-4: Behavioral and Cognitive Symptoms - ASSESSMENT and B-5: Behavioral and Cognitive Symptoms - TREATMENT

\section{RECOMMENDATIONS}

1. Patients with concussion/mTBI should be screened for psychiatric symptoms and co-morbid psychiatric disorders (Depression, Post Traumatic Stress, and Substance Use).

2. Treatment of psychiatric/behavioral symptoms following concussion/mTBI should be based upon individual factors and nature and severity of symptom presentation, and include both psychotherapeutic $[\mathrm{SR}=\mathrm{A}]$ and pharmacological $[\mathrm{SR}=\mathrm{I}]$ treatment modalities.

3. Individuals who sustain a concussion/mTBI and present with anxiety symptoms and/or irritability should be provided reassurance regarding recovery and offered a several week trial of pharmacologic agents (See Appendix E) .[SR = I] 
Table B-4. Behavioral and Cognitive Symptoms - ASSESSMENT

\begin{tabular}{|c|c|c|c|c|c|}
\hline $\begin{array}{l}\text { Common Symptoms } \\
\text { Following } \\
\text { Concussion/mTBI }\end{array}$ & $\begin{array}{l}\text { Review } \\
\text { Medications }\end{array}$ & $\begin{array}{l}\text { Lab Tests: } \\
\text { Electrolytes } \\
\text { CBC } \\
\text { TFT }\end{array}$ & $\begin{array}{l}\text { Review } \\
\text { Sleep } \\
\text { Habits }\end{array}$ & $\begin{array}{l}\text { Screen for: } \\
\text { - Depression } \\
\text { - PTSD } \\
\text { - SUD }\end{array}$ & $\begin{array}{l}\text { Differential Diagnosis } \\
\text { or Comorbid Conditions } \\
\text { Include: }\end{array}$ \\
\hline $\begin{array}{l}\text { Fatigue } \\
\text { - Loss of energy } \\
\text { - Getting tired easily }\end{array}$ & $\sqrt{ }$ & $\sqrt{ }$ & $\sqrt{ }$ & $\sqrt{ }$ & \multirow{4}{*}{$\begin{array}{l}\text { - Anxiety disorders } \\
\text { - Chronic Fatigue } \\
\text { Syndrome } \\
\text { - Chronic pain } \\
\text { - Depression or other } \\
\text { mood disorders } \\
\text { - Insomnia } \\
\text { - Metabolic disorders } \\
\text { - Sleep Apnea } \\
\text { - Stress disorders } \\
\text { - Substance use }\end{array}$} \\
\hline $\begin{array}{l}\text { Cognitive difficulties } \\
\text { - Concentration } \\
\text { - Memory } \\
\text { - Decision-making } \\
\end{array}$ & $\sqrt{ }$ & $\sqrt{ }$ & $\sqrt{ }$ & $\sqrt{ }$ & \\
\hline Feeling anxious & $\sqrt{ }$ & $\sqrt{ }$ & $\sqrt{ }$ & $\sqrt{ }$ & \\
\hline $\begin{array}{l}\text { Emotional difficulties } \\
\text { - Feeling depressed } \\
\text { - Irritability } \\
\text { - Poor frustration } \\
\text { tolerance }\end{array}$ & $\sqrt{ }$ & $\sqrt{ }$ & $\sqrt{ }$ & $\sqrt{ }$ & \\
\hline
\end{tabular}

Key: CBC-complete blood count; TFT-thyroid function test; PTSD-post-traumatic stress disorder; SUD-substance use disorder

Table B- 5. Behavioral and Cognitive Symptoms - TREATMENT

\begin{tabular}{|c|c|c|c|c|}
\hline $\begin{array}{l}\text { Common Symptoms } \\
\text { Following Concussion/mTBI }\end{array}$ & $\begin{array}{l}\text { Job } \\
\text { Review }\end{array}$ & $\begin{array}{l}\text { Pharmacologic } \\
\text { Treatment }\end{array}$ & $\begin{array}{c}\text { Non-Pharmacologic } \\
\text { Treatment }\end{array}$ & $\begin{array}{l}\text { Referral after failed } \\
\text { response to initial } \\
\text { intervention }\end{array}$ \\
\hline $\begin{array}{l}\text { Fatigue } \\
\text { - Loss of energy } \\
\text { - Getting tired easily }\end{array}$ & $\sqrt{ }$ & $*$ & \multirow{4}{*}{$\begin{array}{l}\text { Reassurance } \\
\text { Encourage regular } \\
\text { scheduled aerobic } \\
\text { exercise } \\
\text { Activity restriction } \\
\text { adjustment } \\
\text { Sleep hygiene } \\
\text { Education } \\
\text { Sleep study }\end{array}$} & - Mental Health \\
\hline $\begin{array}{l}\text { Cognitive difficulties } \\
\text { - Concentration } \\
\text { - Memory } \\
\text { - Decision-making } \\
\end{array}$ & $\sqrt{ }$ & $\begin{array}{l}\text { SSRI } \\
*\end{array}$ & & $\begin{array}{l}\text { Consider referral to: } \\
\text { - Cognitive rehabilitation } \\
\text { - Mental Health } \\
\text { - TBI specialist }\end{array}$ \\
\hline Feeling anxious & $\sqrt{ }$ & $\begin{array}{l}\text { Anxiolytic (short term) } \\
\text { SSRI }\end{array}$ & & \multirow[b]{2}{*}{$\begin{array}{l}\text { - Mental Health } \\
\text { - Social support }\end{array}$} \\
\hline $\begin{array}{l}\text { Emotional difficulties } \\
\text { - Feeling depressed } \\
\text { - Irritability } \\
\text { - Poor frustration tolerance }\end{array}$ & $\sqrt{ }$ & $\begin{array}{l}\text { Anti epileptics } \\
\text { SSRI }\end{array}$ & & \\
\hline
\end{tabular}

* Consider in the specialty care setting after ruling out a sleep disorder 


\subsection{Pharmacotherapy}

\section{BACKGROUND}

At present, there is no clinically validated specific brain targeted pharmacotherapy that will ameliorate the neurocognitive effects attributed to TBI (e.g., enhancing memory and attention, recovering from the brain injury). No medication has received approval from the United States Food and Drug Administration (FDA) for the treatment of any neurological or psychiatric consequence of mTBI.

There are a number of effective adjunctive treatments for symptoms, that when used appropriately and cautiously can improve neurological and functional outcome. While there is little empiric evidence, some experts prescribe medications for attention, irritability, sleep, and mood disorders.

\section{Table B-6. Considerations in Using Medication for Treatment of Symptoms}

- Avoid medications that lower the seizure threshold (e.g., bupropion or traditional antipsychotic medications) or those that can cause confusion (e.g., lithium, benzodiazepines, anticholinergic agents).

- Before prescribing medications, rule out social factors (abuse, neglect, caregiver conflict, environmental issues).

- Unless side effects prevail, give full therapeutic trials at maximal tolerated doses before discontinuing a medication trial. Under-treatment is common. Start low and go slow with titration trials.

- Brain injured patients are more sensitive to side effects: watch closely for toxicity and drug-drug interactions.

- Limit quantities of medications with high risk for suicide as the suicide rate is higher in this population.

- Educate patients and family/care givers to avoid the use of alcohol with the medications.

- Minimize caffeine and avoid herbal, diet supplements such as "energy" products as some contain agents that cross-react with the psychiatric medications and lead to a hypertensive crisis.

- Avoid medications that contribute to cognitive slowing, fatigue or daytime drowsiness.

For suggested classes of medication treatment for specific symptoms, see Tables B-3 and B-5.

For selected agents, dosages, and pharmacological data, see Appendix E.

\section{RECOMMENDATIONS}

1. Medication for ameliorating the neurocognitive effects attributed to concussion $/ \mathrm{mTBI}$ is not recommended.

2. Treatment of concussion/mTBI should be symptom-specific.

3. Medications may be considered for headaches, musculoskeletal pain, depression/anxiety, sleep disturbances, chronic fatigue or poor emotional control or lability.

4. Appropriate and aggressive pain management strategies should be employed.

5. When prescribing any medication for patients who have sustained a concussion $/ \mathrm{mTBI}$, the following should be considered:

a. Review and minimize all medication and over-the-counter supplements that may exacerbate or maintain symptoms

b. Use caution when initiating new pharmacologic interventions to avoid the sedating properties that may have an impact upon a person's attention, cognition, and motor performance. 
c. Recognize the risk of overdose with therapy of many medication classes (e.g., tricyclics). Initial quantities dispensed should reflect this concern.

d. Initiate therapy with the lowest effective dose, allow adequate time for any drug trials, and titrate dosage slowly based on tolerability and clinical response.

e. Document and inform all those who are treating the person of current medications and any medication changes.

\subsection{Physical Rehabilitation}

\section{BACKGROUND}

Therapeutic exercise has been shown to positively impact the vast majority of disabilities. These exercises can be general and directed at an overall improvement in cardiopulmonary health, physical strength and power and overall well-being; or focused at specific musculoskeletal, sensory or neuromuscular impairments that limit performance of daily activities. Following concussion/mTBI, those individuals that have persistent symptoms will often lapse in their overall conditioning. This will in turn result in a decrease in short- and long-term global health (physical and behavioral) and put them at an elevated risk for disability, pain, and handicap (i.e., difficulty with return to work, maintaining peer networks.)

\section{RECOMMENDATIONS}

1. There is no contraindication for return to aerobic, fitness and therapeutic activities after concussion/mTBI. Non-contact, aerobic and recreational activities should be encouraged within the limits of the patient's symptoms to improve physical, cognitive and behavioral complaints and symptoms after concussion/mTBI. [SR $=\mathrm{B}]$

2. Specific vestibular, visual, and proprioceptive therapeutic exercise is recommended for dizziness, disequilibrium, and spatial disorientation impairments after concussion/mTBI. (See Appendix D)

3. Specific therapeutic exercise is recommended for acute focal musculoskeletal impairments after concussion/mTBI.

\subsubsection{General Exercise}

Symptoms of concussion/mTBI amenable to general fitness programs are multiple somatic complaints without specific identified mechanisms of injury and an absence of physical findings. The type of exercise (strength training, core stability, aerobic activities, ROM) is no different than those recommended for individuals without concussion/mTBI. However, one should consider a gradual increase in duration and intensity due to the activity intolerance and fatigue that is commonly associated with concussion/mTBI. Implementation of a scheduled daily routine and incorporation of peer networks may improve compliance.

\subsubsection{Focused Exercise}

Focal impairments (e.g., upper cervical root entrapment, impaired gaze stability, oculomotor dysfunction) benefit from tailored exercise programs that promote adaptation of or compensation for the affected systems (vestibular, visual, and proprioceptive) or specific musculoskeletal/neuromuscular impairments (decreased ROM, weakness, timing). The exercises that are commonly prescribed for these systems/impairments will be warranted. It is the delivery of instruction, guidance and follow-up needs that will be greater for those with mTBI. As well, the duration and intensity level may need to be considered when looking at the overall presentation of the individual.

\subsection{Alternative Modalities}

\section{BACKGROUND}

The vast majority of individuals with concussion/mTBI will have no difficulties or complaints following injury. While early interventions have been shown to prevent and treat persistent somatic, cognitive and behavioral deficits, certain individuals will have persistent difficulties. Additionally, a 
significant percentage of individuals with concussion/mTBI will not receive early diagnosis or will not seek treatment, and therefore their symptoms will be addressed only after a temporal delay. In many of these individuals with chronic persistent symptoms after mTBI, traditional medical interventions are less than successful. Complementary alternative medicine (CAM) may be sought by the patient or patient's family. CAM interventions may assist in the treatment of certain symptoms associated with concussion/mTBI. An evidence-based approach to the implementation of complementary medicine strategies will be useful to prevent over- or underutilization of CAM.

- Acupuncture

- Bio-feedback

Novel therapy (hyperbaric oxygen, nutritional supplements) modalities in the management of concussion/mTBI are being explored in the field as potential treatment approaches. It is the recommendation of the Working Group that interventions which lack sufficient empirical support should occur only under the auspices of an IRB reviewed protocol. However, complementary techniques such as acupuncture may be used at the discretion of the provider and patient.

\section{RECOMMENDATIONS}

1. Complementary-alternative medicine treatments may be considered as adjunctive treatments or when requested by individuals with concussion/mTBI. [SR $=\mathrm{I}]$

Annotation B-9 $\quad$ Follow-Up and Assess in 4-6 Weeks

\section{Follow-Up}

\section{RECOMMENDATIONS}

1. All patients should be followed up in $4-6$ weeks to confirm resolution of symptoms and address any concerns the patient may have.

2. Follow-up after the initial interventions is recommended in all patients to determine patient status. The assessment will determine the following course of treatment:

a. Patient recovers from acute symptoms - provide contact information with instructions for available follow-up if needed.

b. Patient demonstrates partial improvement (e.g., less frequent headaches, resolution of physical symptoms, but no improvement in sleep) - consider augmentation or adjustment of the current intervention and follow-up within 4-6 weeks.

c. Patient does not improve or status worsens - Focus should be given to other factors including psychiatric, psychosocial support, and compensatory/litigation. Referral to a specialty provider should be considered. 


\title{
C: Follow-Up Management of Persistent Concussion/mTBI Symptoms
}

\author{
Annotation C-1 Person Diagnosed with Concussion/mTBI and Persistent Symptoms Beyond 4-6 Weeks \\ Follow-Up
}

The vast majority of individuals with concussion/mTBI will have no difficulties or complaints following injury. While early interventions have been shown to prevent physical, cognitive and behavioral deficits, certain individuals will have persistent difficulties. Additionally, a significant percentage of individuals with concussion/mTBI will not receive early diagnosis or will not seek treatment, and therefore their symptoms will be addressed only after a temporal delay. This guideline recommends that these individuals should first be treated following the algorithm and annotations in the sections addressing initial presentation and diagnosis. For patients with symptoms that do not respond to initial treatment, the recommendations in this section will apply. This section also includes suggestions for further evaluations and for referrals to specialty providers.

Annotation C-2 Reassess Symptom Severity and Functional Status

Complete Psychosocial Evaluation

\section{Assessment of Persistent Symptoms}

\section{BACKGROUND}

In patients with persistent post-concussive symptoms that have been refractory to treatment, consideration should be given to other factors including behavioral health (e.g., stress disorders, mood disorders, and substance use disorders), psychosocial support, and compensation/litigation.

\section{RECOMMENDATIONS}

1. Follow-up after the initial interventions is recommended in all patients with concussion/mTBI to determine patient status and the course of treatment.

2. Evaluation of patients with persistent symptoms following concussion/mTBI should include assessment for dangerousness to self or others.

3. In assessment of patients with persistent symptoms, focus should be given to other factors including psychiatric, psychosocial support, and compensation/litigation issues and a comprehensive psychosocial evaluation should be obtained, to include:

a. Support systems (e.g., family, vocational)

b. Mental health history for pre-morbid conditions which may impact current care

c. Co-occurring conditions (e.g., chronic pain, mood disorders, stress disorder, personality disorder)

d. Substance use disorder (e.g., alcohol, prescription misuse, illicit drugs, caffeine)

e. Secondary gain issues (e.g., compensation, litigation)

f. Unemployment or/change in job status

g. Other issues (e.g., financial/housing/legal). 


\section{DISCUSSION}

Table C-1 includes key domains of functional assessment and suggested questions to guide the patient assessment.

Table C-1. Functional Assessment

\begin{tabular}{|c|c|}
\hline Work & $\begin{array}{l}\text { - Have there been any changes in productivity? } \\
\text { - Have co-workers or supervisors commented on any recent changes in } \\
\text { appearance, quality of work, or relationships? } \\
\text { - Is there an increase in tardiness, loss of motivation, or loss of interest? } \\
\text { - Has the patient been more forgetful, easily distracted? }\end{array}$ \\
\hline School & $\begin{array}{l}\text { - Have there been changes in grades? } \\
\text { - Have there been changes in relationships with friends? } \\
\text { - Has there been a recent onset or increase in acting-out behaviors? } \\
\text { - Has there been a recent increase in disciplinary actions? } \\
\text { - Has there been increased social withdrawal? } \\
\text { - Has there been a change in effort required to complete assignments? }\end{array}$ \\
\hline $\begin{array}{l}\text { Family } \\
\text { Relationships }\end{array}$ & $\begin{array}{l}\text { - Have there been negative changes in relationship with significant } \\
\text { others? } \\
\text { - Is the patient irritable or easily angered by family members? } \\
\text { - Has there been a withdrawal of interest in or time spent with family? } \\
\text { - Has there been any violence within the family? }\end{array}$ \\
\hline Housing & $\begin{array}{l}\text { - Does the patient have adequate housing? } \\
\text { - Are there appropriate utilities and services? } \\
\text { - Is the housing situation stable? }\end{array}$ \\
\hline Legal & $\begin{array}{l}\text { - Are there outstanding warrants, restraining orders, or disciplinary } \\
\text { actions? } \\
\text { - Is the person regularly engaging in, or at risk to be involved in, illegal } \\
\text { activity? } \\
\text { - Is the patient on probation or parole? } \\
\text { - Is the patient seeking litigation for compensation? } \\
\text { - Is there family advocacy/Department of Social Services (DSS) } \\
\text { involvement? }\end{array}$ \\
\hline Financial & $\begin{array}{l}\text { - Does the patient have the funds for current necessities including food, } \\
\text { clothing, and shelter? } \\
\text { - Is there a stable source of income? } \\
\text { - Are there significant outstanding or past-due debts, alimony, child } \\
\text { support? } \\
\text { - Has the patient filed for bankruptcy? } \\
\text { - Does the patient have access to healthcare and/or insurance? }\end{array}$ \\
\hline $\begin{array}{l}\text { Unit/Community } \\
\text { Involvement }\end{array}$ & $\begin{array}{l}\text { - Does the patient need to be put on profile, MEB, or limited duty? } \\
\text { - Is the patient functional and contributing in the unit environment? } \\
\text { - Is there active/satisfying involvement in a community group or } \\
\text { organization? }\end{array}$ \\
\hline
\end{tabular}


Annotation C-3 Assess for Possible Alternative Causes for Persistent Symptoms

\subsection{Risk Factors for Persistent Post-Concussive Symptoms}

\section{BACKGROUND}

Identifying risk factors for persisting symptoms and understanding the relationship between risk factors and short- and long-term outcomes can help enhance assessment and treatment. Some risks are pre-existing factors that may predispose an individual to worse outcomes following a concussion/mTBI; others are potentially directly causative (e.g., the injury itself or medical/legal iatrogenic factors); and still others are potentially perpetuating factors which may occur during the peri-injury or post-injury timeframe.

Table C-2. Risk Factors for Persistent Symptoms and/or Poorer Overall Outcomes

\begin{tabular}{|l|l|l|}
\hline Pre-injury & Peri-injury & Post-injury \\
\hline - Age (older) & - Lack of support system & - Compensation \\
- Gender (female) & - Acute symptom & - Litigation (malingering, \\
- Low SES & presentation (e.g., & delayed resolution) \\
- Less education / Lower levels & headaches, dizziness, or & - Co-occurrence of \\
of intelligence & nausea in the ER) & psychiatric disorders \\
- Pre-neurological conditions & - Context of injury (stress, & - Co-occurrence of chronic \\
- Pre- or co-occurrence of & combat-related, & pain conditions \\
mental health disorders & traumatic) & - Lack of support system \\
(depression, anxiety, & & - Low education \\
traumatic stress, or & & \\
substance use) & & \\
\hline
\end{tabular}

Bold text indicates support of Level C evidence

\section{RECOMMENDATIONS}

1. Assessment of the patient with concussion/mTBI should include a detailed history regarding potential pre-injury, peri-injury, or post-injury risk factors for poorer outcomes. These risk factors include:

a. Pre-injury: older age, female gender, low socio-economic status, low education or lower levels of intellectual functioning, poorer coping abilities or less resiliency, pre-existing mental health conditions (e.g., depression, anxiety, PTSD, substance use disorders).

b. Peri-injury: lower levels of or less available social support

c. Post-injury: injury-related litigation or compensation, comorbid mental health conditions or chronic pain, lower levels of or less available social support,

2. Any substance abuse and/or intoxication at the time of injury should be documented.

3. Establish and document if the patient with concussion/mTBI experienced headaches, dizziness, or nausea in the hours immediately following the injury. 


\subsection{Compensation Seeking/Non-Validated Symptoms}

\section{BACKGROUND}

The majority of people with concussion/mTBI will have no difficulties or complaints following injury. However, a minority of patients will continue to have ongoing symptoms that may result in a disability. Though these symptoms lose specificity with time and may be wrongly attributed to the $\mathrm{mTBI} /$ concussion, they may also interfere with an individual's recovery. Even after a careful differential diagnosis, it remains a challenge for providers to quantify non-specific, subjective complaints for the purposes of disability compensation.

\section{RECOMMENDATIONS}

1. Symptom exaggeration or compensation seeking should not influence the clinical care rendered, and doing so can be counter-therapeutic and negatively impact the quality of care.

2. Focus of the provider-patient interaction should be on the development of a therapeutic alliance $(\mathrm{SR}=\mathrm{C})$.

\subsection{Persistent Post-Concussive Symptoms (PPCS)}

\section{BACKGROUND}

For concussion/mTBI patients, most symptoms and signs that occur in the acute period resolve quickly (within hours or days) after the injury. There is debate about the incidence of developing persistent symptoms after concussion, largely due to the lack of an accepted case definition for persistent symptoms and the fact that none of the symptoms are specific to concussion. There is no consensus on a case definition for persistent symptoms attributed to concussion/mTBI and no consensus on the time course when acute symptoms should be considered persistent.

See discussion in Section 1.6 Persistent Symptoms after Concussion and Table C-3 Post-Concussion Symptoms.

Table C-3. Post-Concussion Symptoms

\begin{tabular}{|c|c|c|}
\hline Somatic Symptoms & Psychological & Cognitive \\
\hline 0 Headache * & o Problems controlling & o Problems with memory * \\
\hline Fatigue * & emotions * & o Cognitive disorders $*$ \\
\hline Sensitivity to light/noise * & o Irritability * & o Problems with concentration $*$ \\
\hline Insomnia \& sleep disturbances * & o Anxiety * & o Functional status limitations * \\
\hline Drowsiness * & o Depression * & \\
\hline o Dizziness * & & \\
\hline o Nausea \& vomiting * & & \\
\hline o Vision problems * & & \\
\hline o Transient neurological abnormalities & & \\
\hline o Seizures & & \\
\hline o Balance problems & & \\
\hline
\end{tabular}

\section{RECOMMENDATIONS}

1. For clinical treatment purposes the use of post-concussion syndrome, post-concussive syndrome (PCS) or post-concussion disorder (PCD) as a diagnosis is not recommended. The unique individual pattern of symptoms should be documented and be the focus of treatment.

For the purpose of this CPG, the term persistent post-concussive symptoms will be used. 
Annotation C-4 Any Behavioral Health Diagnosis Established?

\subsection{Persistent Behavioral Symptoms}

\section{BACKGROUND}

Patients with persistent post-concussive symptoms have a higher incidence of co-occurring mental health conditions (e.g., Stress disorders [ASD, PTSD]), other anxiety disorders, mood disorders, Substance Use Disorders[SUD]) and a pre-injury history of mental health conditions.

In patients with persistent post-concussive symptoms (PPCS), that have been refractory to treatment, a referral to mental health may help elucidate other factors which may be involved in the exacerbation or maintenance of concussion symptoms. These include prior psychiatric history, lack of psychosocial support, financial compensation/litigation, chronic pain, and somatoform spectrum disorders.

See Table C-6: Behavioral Symptoms - TREATMENT

\section{RECOMMENDATIONS}

1. Patients with persistent symptoms following concussion/mTBI should be re-evaluated for psychiatric symptoms and co-morbid psychiatric disorders.

2. Treatment of psychiatric symptoms following concussion/mTBI beyond the acute phase should still be based on individual factors and nature and severity of symptom presentation, including psychotherapeutic $[\mathrm{SR}=\mathrm{A}]$ and pharmacologic $[\mathrm{SR}=\mathrm{I}]$ treatment modalities.

3. In patients with persistent post-concussive symptoms (PPCS), which have been refractory to treatment, consideration should be given to other factors including psychiatric disorders, lack of psychosocial support, and compensation/litigation.

Annotation C-5 Consider Referral to Specialty Care

\section{Consultation and Referral}

\section{RECOMMENDATIONS}

1. A consultation or referral to specialists should occur in a patient with concussion/mTBI who complains of persistent or chronic symptoms when:

a. An atypical pattern or course (worsening or variable symptom presentation) is demonstrated

b. The patient is experiencing difficulties in return to pre-injury activity (work/duty/school)

c. Problems emerge in the role of the patient in family or social life.

2. Patients with multiple problems may benefit from an interdisciplinary approach to include occupational therapy, recreation therapy, social work, psychology and/or psychiatry, neurology, ENT, ophthalmology or audiology, based on individual symptoms. The patient's provider should remain involved in the patient's care.

3. Referral to mental health specialty of patients with persistent behavioral symptoms should be considered.

See Table C-4 Indications for Referral to Mental Health 


\section{Table C-4. Indications for Referral to Mental Health}

\begin{tabular}{|ll|}
\hline o & Failure to respond to acute supportive interventions \\
o & Worsening of stress related symptoms \\
o & High potential for dangerousness \\
o & Development of PTSD \\
0 & Exacerbation of pre-existing psychiatric conditions \\
o & Deterioration in function \\
o & New onset stressors, poor social supports or inadequate \\
& coping skills \\
o & Impairment in family or vocational role function \\
& \\
\hline
\end{tabular}

Annotation C-6 Any Persistent Symptoms (Physical, Cognitive or Emotional)?

\subsection{Persistent Physical Symptoms}

\section{RECOMMENDATIONS}

1. Patients who are refractory to treatment of physical symptoms in the initial care setting should be referred to specialty care for further evaluation and management (See Appendix D - Treatment of Physical Symptoms).

See Table C-5 Persistent Physical Symptoms - TREATMENT

\subsection{Persistent Cognitive Difficulties}

\section{BACKGROUND}

Although initial cognitive complaints and problems are common in the first hours and days after a concussion/mTBI, the vast majority of individuals recover within one to four weeks. However, a small minority either continue to report cognitive problems or report worsening symptoms over the months and even years post-injury. This subgroup frequently has premorbid or comorbid conditions such as depression, anxiety, poor health, and chronic pain or poor psychosocial support or other coping resources.

Assistive technology for cognition (ATC) refers to a subset of assistive technology used to compensate for cognitive impairments in memory, attention, and executive function. Devices in this category are also known as memory aids or cognitive prostheses. They are designed to assist individuals with concussion/mTBI to carry out everyday tasks by providing cues or limiting demands on impaired cognitive skills. Devices can range from simple electronic tools, such as a wrist watch with an alarm function to sophisticated personal digital assistants and global positioning systems. Successful longterm utilization of ATC by persons with concussion/mTBI requires selection of appropriate devices and effective training using the device in real-life contexts.

See Table C-6 Persistent Cognitive Symptoms - TREATMENT

\section{RECOMMENDATIONS}

1. Patients who have cognitive symptoms that do not resolve or have been refractory to treatment should be considered for referral for neuropsychological assessment. The evaluation may assist in clarifying appropriate treatment options based on individual patient characteristics and conditions. $[\mathrm{SR}=\mathrm{B}]$

2. Neuropsychological testing should only be conducted with reliable and standardized tools by trained evaluators, under controlled conditions, and findings interpreted by trained clinicians. [SR $=\mathrm{C}]$ 
3. Individuals who present with memory, attention, and/or executive function problems which did not respond to initial treatment (e.g., reassurance, sleep education, or pain management) may be considered for referral to cognitive rehabilitation therapists with expertise in TBI rehabilitation (e.g., speech and language pathology, neuropsychology, or occupational therapy) for compensatory training $[\mathrm{SR}=\mathrm{C}]$; and or instruction and practice on use of external memory aids such as a PDA. $[\mathrm{SR}=\mathrm{C}]$

Table C-5. Persistent Physical Symptoms - TREATMENT

\begin{tabular}{|c|c|c|c|}
\hline $\begin{array}{l}\text { Common Symptoms } \\
\text { Following } \\
\text { concussion } / \mathrm{mTBI}\end{array}$ & $\begin{array}{l}\text { Pharmacologic } \\
\text { Treatment }\end{array}$ & $\begin{array}{l}\text { Non-Pharmacologic } \\
\text { Treatment }\end{array}$ & $\begin{array}{c}\text { Referral After Failed } \\
\text { Response to Initial } \\
\text { Treatment }\end{array}$ \\
\hline Headaches & $\begin{array}{ll}\text { - } & \text { Non narcotic pain meds } \\
\text { - } & \text { NSAIDs } \\
\text { - } & \text { Triptans (migraine type) }\end{array}$ & $\begin{array}{ll}\text { - } & \text { Sleep education } \\
\text { - } & \text { Physical therapy } \\
\text { - } & \text { Relaxation }\end{array}$ & $\begin{array}{l}\text { Neurology } \\
\text { Pain clinic }\end{array}$ \\
\hline Feeling dizzy & $\begin{array}{l}\text { Antibiotics, decongestants for } \\
\text { infections and fluid }\end{array}$ & - & $\begin{array}{l}\text { Dizzy : ENT/Neurology } \\
\text { after ENT interventions }\end{array}$ \\
\hline $\begin{array}{l}\text { Loss of balance } \\
\text { Poor coordination }\end{array}$ & - & - Physical therapy & Neurology \\
\hline Nausea & - Antiemetics & - Sleep education & GI \\
\hline Change in appetite & - & - & Consider Mental Health \\
\hline $\begin{array}{l}\text { Sleep disturbances } \\
\text { - Difficulty falling or } \\
\text { staying a sleep } \\
\text { (insomnia) }\end{array}$ & - Sleep Medications & - Sleep education & $\begin{array}{l}\text { Mental health } \\
\text { PM\&R } \\
\text { Neurology }\end{array}$ \\
\hline $\begin{array}{l}\text { Vision problems } \\
\text { - Blurring } \\
\text { - Trouble seeing } \\
\text { - Sensitivity to light } \\
\end{array}$ & - & $\begin{array}{ll}\text { - } & \text { Sleep education } \\
\text { - } & \text { Light desensitization } \\
\text { - } & \text { Sunglasses }\end{array}$ & $\begin{array}{l}\text { Optometry } \\
\text { Ophthalmology ** }\end{array}$ \\
\hline $\begin{array}{l}\text { Hearing difficulty } \\
\text { - Sensitivity to noise }\end{array}$ & - & $\begin{array}{l}\text { Environmental } \\
\text { modifications }\end{array}$ & $\begin{array}{l}\text { Audiology } \\
\text { ENT } \\
\text { Sensitivity to Noise : } \\
\text { Speech and Language } \\
\text { Pathology }\end{array}$ \\
\hline
\end{tabular}

Depending on the local resources, impaired vision may be referred in some facilities to neuro-ophthalmologists.

Note that the impaired vision may be due to problems with oculomotility as well as due to disorders of the retina and visual pathways. 
Table C-6. Persistent Behavioral and Cognitive Symptoms - TREATMENT

\begin{tabular}{|c|c|c|c|c|}
\hline $\begin{array}{c}\text { Common Symptoms } \\
\text { Following } \\
\text { Concussion/mTBI }\end{array}$ & $\begin{array}{c}\text { Job } \\
\text { Review }\end{array}$ & $\begin{array}{l}\text { Pharmacologic } \\
\text { Treatment }\end{array}$ & $\begin{array}{c}\text { Non-Pharmacologic } \\
\text { Treatment }\end{array}$ & $\begin{array}{l}\text { Referral After Failed } \\
\text { Response to Initial } \\
\text { Intervention }\end{array}$ \\
\hline $\begin{array}{l}\text { Fatigue } \\
\text { - Loss of energy } \\
\text { - Getting tired easily }\end{array}$ & $\sqrt{ }$ & Stimulant* & \multirow{4}{*}{$\begin{array}{l}\text { Reassurance } \\
\text { Encourage regular } \\
\text { scheduled aerobic } \\
\text { exercise } \\
\text { Activity restriction } \\
\text { adjustment } \\
\text { Sleep hygiene } \\
\text { Education } \\
\text { Sleep study }\end{array}$} & - Mental Health \\
\hline $\begin{array}{l}\text { Cognitive difficulties } \\
\text { - Concentration } \\
\text { - Memory } \\
\text { - Decision-making }\end{array}$ & $\sqrt{ }$ & $\begin{array}{l}\text { SSRI } \\
\text { Stimulant* }\end{array}$ & & $\begin{array}{l}\text { - TBI specialist for } \\
\text { cognitive rehabilitation or } \\
\text { mental health }\end{array}$ \\
\hline Feeling anxious & $\sqrt{ }$ & $\begin{array}{l}\text { Anxiolytic (short term) } \\
\text { SSRI }\end{array}$ & & \\
\hline $\begin{array}{l}\text { Emotional difficulties } \\
\text { - Feeling depressed } \\
\text { - Irritability } \\
\text { - Poor frustration } \\
\quad \text { tolerance }\end{array}$ & $\sqrt{ }$ & $\begin{array}{l}\text { Anti epileptics } \\
\text { SSRI }\end{array}$ & & $\begin{array}{l}\text { - Mental Health } \\
\text { - Social support }\end{array}$ \\
\hline
\end{tabular}

* Consider in the specialty care setting after ruling out a sleep disorder

Annotation C-7 Consider Referral to Occupational or Vocational Therapy and Community Integration Programs (Continue Case Management)

\section{Rehabilitation of Patients with Persistent Post-Concussive Symptoms (PPCS)}

\section{BACKGROUND}

\section{Role of Consultants}

For patients who will be referred to specialty care, treatment will be provided by the specialty consultant as recommended in the management of specific symptoms or other clinical practice guidelines. The referring care provider is expected to serve as the focal point for an inter-disciplinary approach to treatment that may span the continuum of care. With patient consent, it may be found useful to involve the patient's employer/supervisor, spouse, and friends and significant others within the patient's social support network.

In patients with persistent post-concussive symptoms (PPCS), the role of mental health providers (psychiatry, psychology, neuropsychology, social work, and others) will be more essential in providing input into implementing psychotherapeutic treatment in the outpatient setting. Social workers should help build family and social support networks, or recommend changes in the patient's living situation, in order to create a positive support network.

\subsection{Case Management in the Care of Patients with mTBI}

\section{BACKGROUND}

Patients presenting with symptoms should be considered both initially and on an ongoing basis for referral to case management. Whether the patient has recently returned from deployment or combat, or is a veteran who has sustained non-combat related head trauma, the need for a collaborative and coordinated approach to comprehensive care is necessary. 


\section{Table C- 7 Case Managers Serve Multiple Functions}

- Complete an in-depth assessment of functional status and coordinate treatment resources

- Ensure that the patient is screened for social service needs and mental health problems.

- Assure that referrals are coordinated and made as appropriate to the responsible discipline

- Ensure that the patient and family have received appropriate education

- Participate in setting short- and long-term goals

- Assist in the process of moving between facilities and levels of care

- Monitor patient progress

- Coordinate and collaborate with the multi-disciplinary team

\section{RECOMMENDATIONS}

1. Patients with persistent symptoms following concussion/mTBI may be considered for case management.

2. Case managers should complete a comprehensive psychosocial assessment of the patient and the patient's family. It may be necessary or beneficial to meet with other members of the patient's support system (family, care giver) and/or invite the patient to ask them to come to an appointment together with the patient.

3. Case managers should collaborate with the treatment team, the patient, and the patient's family in developing a treatment plan that emphasizes the psychosocial needs of the patient.

4. Case managers (in collaboration with the treatment team) should prepare and document a detailed treatment plan in the medical record describing follow-up care and services required.

5. Case managers who provide care in the clinical setting should communicate and coordinate with other potential care coordinators that provide care for the patient (such as a VHA social worker liaison or military social worker at the referring Military Treatment Facility, Patient Treatment Advocate (PTA)).

6. Case managers may provide assistance to the patient and family who are transferred to another facility (e.g., a polytrauma rehabilitation center).

7. Case management may serve as the main point of contact for the patient and family. This may include the following :

a. Provide the patient with contact information including after hours calls

b. Maintain frequent contact by phone to remind about or facilitate an appointment

c. Facilitate access to supportive services to the patient and family

d. Serve as a liaison for the patient's family and as an advocate for the patient and the patient's family

e. Provide easy-to-understand information in writing for the patient and the patient's family.

\subsection{Patient and Family Education}

\section{RECOMMENDATIONS}

1. All members of the treatment team should be involved in patient education as part of their interaction with the patient experiencing persistent symptoms.

2. Educational interventions should generally include information and a description of the specific procedures and events the patient will experience at the various phases of treatment and continue throughout the continuum of care.

3. General supportive counseling (e.g., eliciting and validating the patient's anxieties, fears, and concerns) may also be helpful. Open-ended questioning, active listening techniques, eliciting anticipation of future stressors, encouraging the patient to ask questions, and eliciting and 
encouraging utilization of the patient's social support resources are important strategies regardless of whether information-giving or coping skills training interventions are being used.

4. Educational interventions may also include coping techniques for symptom management, such as patient education handouts and helpful tips.

\subsection{Functional and Vocational Activities}

\section{BACKGROUND}

A return to the normal patterns of daily life and safe, independent living requires a practical, individualized application of therapeutically-based treatment. This includes the assessment and reestablishment of structured routines in daily activities, marriage/family dynamics, educational activities, vocation, and community involvement.

The emphasis of the team at this point is to enhance functional outcome and reduce disability associated with the symptoms. This is accomplished by treatment that improves patient function and by interventions that mitigate and adjust the environment in which the patient is expected to function (e.g., family, vocational and community).

Potentially modifiable psychosocial barriers to patient functioning could include the following:

Living environment-Homelessness can perpetuate chronic illness as the result of environmental exposure and virtually non-existent personal hygiene.

Support systems - Negative supports on the part of the spouse, family, or significant other can impair and even worsen functionality.

Job-Work place factors have been associated with illness-related behavior.

Finances-Disability compensation can perpetuate illness by requiring continuing symptoms and disability for the worker to be eligible for benefits.

\section{RECOMMENDATIONS}

\section{Family Support}

1. As with other chronic conditions, the focus of the management of patients with persistent symptoms following concussion/mTBI should shift to the psychological and social impacts on the patient.

2. The clinician should consider having the spouse or partner accompany the patient with concussion/mTBI to a consultation, to help them better understand the condition and provide an opportunity to discuss any coping difficulties.

3. Family members should be encouraged to consider joining a support group to provide education, advice and opportunities to exchange coping strategies for dealing with the day-to-day difficulties of living with an individual with persistent symptoms following concussion/mTBI.

\section{Vocational Rehabilitation}

1. Vocational interventions for the patient with persistent symptoms following concussion/mTBI may include modifications such as:

- Modification of the length of the work day

- Gradual work re-entry (e.g., starting at 2 days/week and expanding to 3 days/week)

- Additional time for task completion

- Change of job

- Environmental modifications (e.g., quieter work environment; enhanced level of supervision) 
2. Patients who have not successfully resumed pre-injury work duties following injury should be referred for a vocational evaluation by clinical specialists with expertise in assessing and treating concussion/mTBI.

3. For patients with persistent symptoms following concussion/mTBI, return to full work/duty in the jobs they have previously preformed may not be possible. Patients may need to proceed through medical or disability evaluation processes. This process should follow national and local regulations and is beyond the scope of the guideline.

\section{Community participation}

4. A referral to a structured program that promotes community integration may be considered for individuals with residual persistent post-concussive symptoms that impede return to pre-injury participation in customary roles.

Annotation C- $8 \quad$ Follow-Up and Reassess in 3-4 Months

\section{FOLLOW-UP}

\section{BACKGROUND}

The goal of follow-up visits is to monitor the severity of symptoms, impact of the symptoms on activities, effects of treatments, and presence of adverse effects to treatments, and to assess patients for new symptoms suggestive of other diagnoses.

Although natural improvement is generally expected, recovery can be prolonged and a minority of patients still have symptoms at 6 months. The use of telephonic and other distance technologies may be used to monitor the recovery process, reinforce education, and prevent development of secondary problems.

\section{RECOMMENDATIONS}

1. Scheduled follow-up visits are recommended. The amount of time between visits will vary depending on a number of factors, including the following:

a. Quality of the provider/patient relationship

- Distress of the patient

- Need for refinement of the treatment plan or additional support

- Presence or absence of psychosocial stressors.

b. Severity of the symptoms

- Initially, a follow-up at two to three weeks would be appropriate

- As soon as the patient is doing well, then follow-up every 3 to 4 months would be recommended

- Telephone follow-up may be sufficient to evaluate resolution of symptoms and reinforce education.

c. For concussion/mTBI patients with complicated histories, comorbidities, and lack of social support consider case management.

2. Continually re-evaluate the patient for worsening of chronic symptoms or presence of new symptoms suggestive of other diagnoses. 


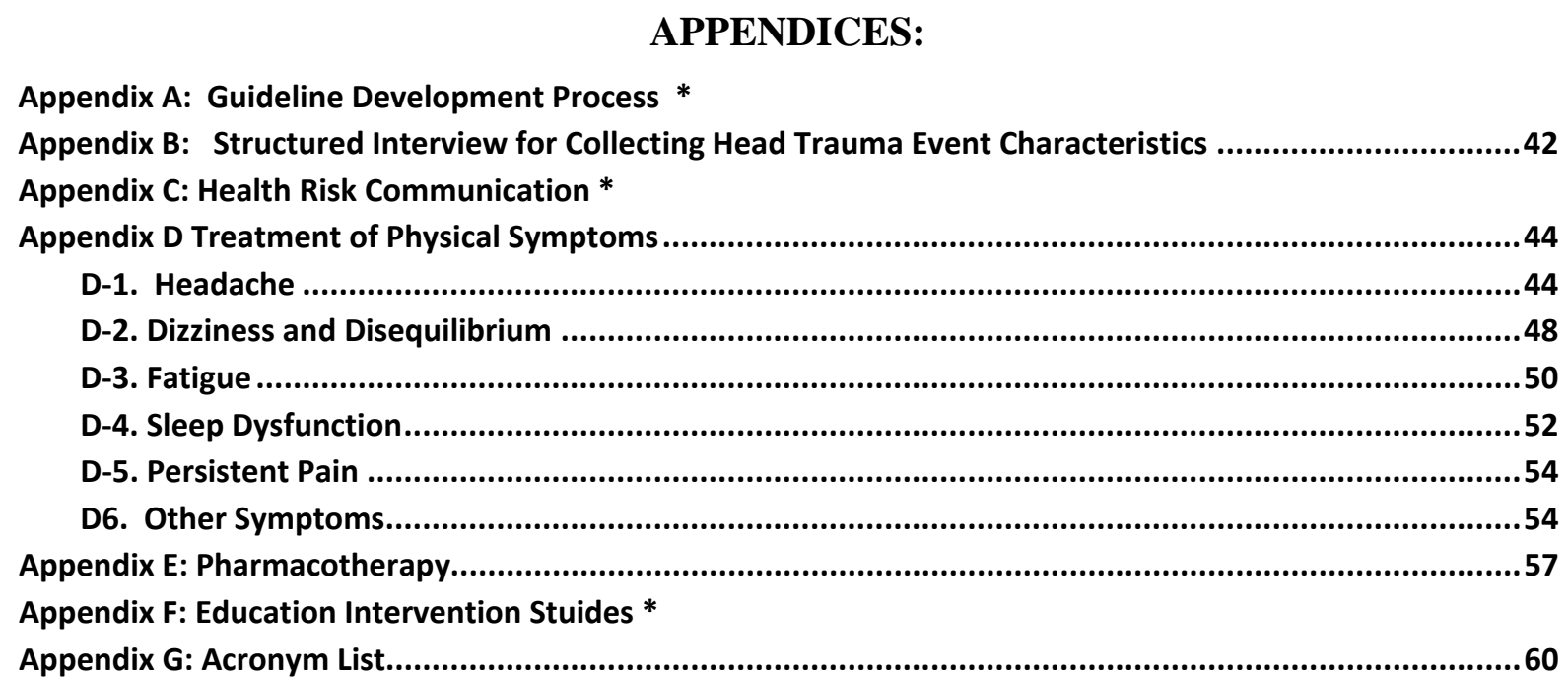

Appendix H: Participant List *

Appendix I: Bibliography *

* Included in the Full Version of the Guideline -www.healthquality.gov/cpg 


\section{Appendix B: \\ Structured Interview for Collecting Head Trauma Event Characteristics}

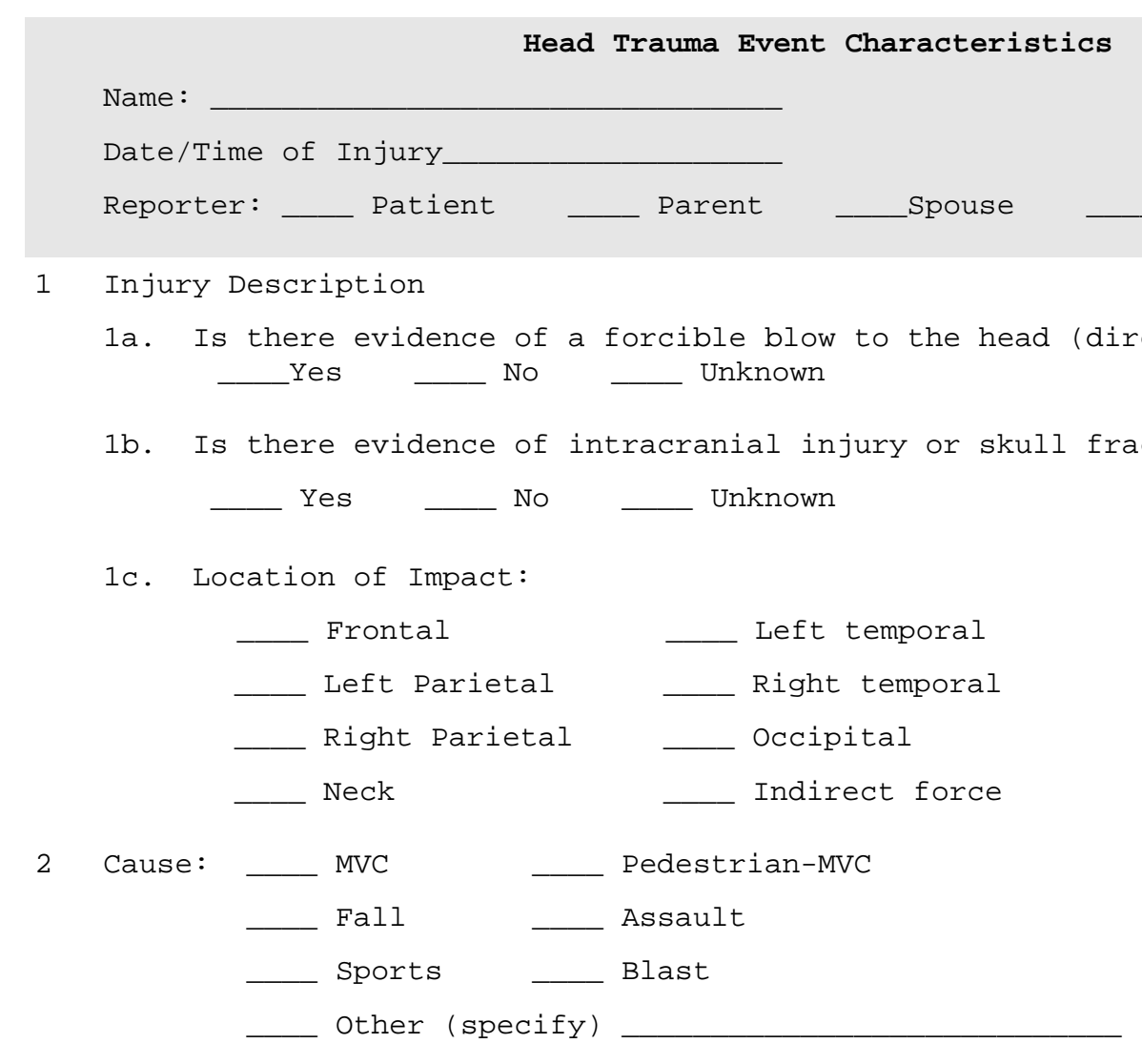

3 Amnesia Before (Retrograde)

Are there any events just BEFORE the injury that you/person has no memory of (even brief)? __ Yes _ No _ _ Duration

4 Amnesia After (Anterograde)

Are there any events just AFTER the injury that you/person has no memory of (even brief)? _ Yes N No Duration

5 Loss of Consciousness

Did you/person lose consciousness? __ Yes __ No Duration

6 EARLY SIGNS

_ Appears dazed or stunned

_ Answers questions slowly Is confused about events Repeats Questions Forgetful (recent info)

7 Were seizures observed? __ No __ Yes Detail

8 Any deaths/injuries to others that occurred as a result of this event? No Yes

Instructions for collecting injury characteristics information: 
Q1 Obtain description of the injury: how injury occurred, type of force, location on the head or body (if force transmitted to head). Different biomechanics of injury result in differential symptom patterns (e.g., occipital blow may result in visual changes, balance difficulties).

Q2 Indicate the cause of injury. Greater forces associated with the trauma are likely to result in more severe presentation of symptoms.

Q3 \& 4 Amnesia: Amnesia is defined as the failure to form new memories. Determine whether amnesia has occurred and attempt to determine length of time of memory dysfunction - before (retrograde) and after (anterograde) injury.

Q5 Loss of consciousness (LOC) - If occurs, determine length of LOC.

Q6 Early signs. If present, ask the individuals who know the patient (parent, spouse, friend, etc) about specific signs of the concussion that may have been observed. These signs are typically observed early after the injury.

Q7 Inquire whether seizures were observed or not.

Q8 Deaths or injuries that occur during an event can contribute to the development of mental health symptoms. 


\section{Appendix D \\ Treatment of Physical Symptoms}

This Appendix includes recommendations for treatment of a selected list of physical symptoms that are most common in patients presenting with symptoms following a concussion $/ \mathrm{mTBI}$. The recommendations were formulated based on Consensus of clinical experts.

\section{D-1. Headache}

\section{BACKGROUND}

Post-traumatic headaches occur acutely in up to $90 \%$ of all individuals who sustain a concussion. Post-traumatic headaches usually develop within 7 days of head trauma. The International Headache Society classification category is headaches associated with head and neck trauma. The category was established because the most frequent forms of civilian head trauma also cause injury to the cervical spinal column, spinal cord and neck musculature. Cervicogenic pain can include headache as well as neck pain. Individuals who sustain head and neck injury can have headaches in which the pain originates from both the head and the neck. Although post-traumatic headaches represent a unique category of headache, they often share features of other types of headaches. The three most common patterns of post-traumatic headaches are:

1. Tension-type headaches, including cervicogenic component

2. Migraine headaches, or

3. Combined migraine and tension-type headaches.

Table D - 1 Criteria for characterizing post-traumatic headaches as tension-like (including cervicogenic) or migraine-like based upon headache features.

\begin{tabular}{|l|l|l|}
\hline \multirow{2}{*}{ Headache Feature } & \multicolumn{2}{|c|}{ Headache Type } \\
\cline { 2 - 3 } & Tension-like (include cerviogenic pain) & Migraine-like \\
\hline Pain Intensity & Usually mild-moderate & Often severe or debilitating \\
\hline Pain Character & $\begin{array}{l}\text { Dull, aching, or pressure. Sharp pain may be } \\
\text { present, but is not predominant }\end{array}$ & $\begin{array}{l}\text { Throbbing or pulsatile, can also be sharp/stabbing } \\
\text { or electric-like }\end{array}$ \\
\hline Duration & Usually less than 4 hours & Can last longer than 4 hours \\
\hline Phono- or photo-phobia & One but not both may be present & One, or both usually present \\
\hline $\begin{array}{l}\text { Able to carry out } \\
\text { routine activities /work }\end{array}$ & Usually & $\begin{array}{l}\text { Usually not, or with a decreased level of } \\
\text { participation }\end{array}$ \\
\hline Location & $\begin{array}{l}\text { Bilateral frontal, retro-orbital, temporal, } \\
\text { cervical and occipital, or holocephalic }\end{array}$ & $\begin{array}{l}\text { Usually unilateral and may vary in location among } \\
\text { episodes }\end{array}$ \\
\hline Nausea or malaise & Not present & Usually present \\
\hline $\begin{array}{l}\text { Palpable muscle } \\
\text { tenderness or } \\
\text { contraction }\end{array}$ & $\begin{array}{l}\text { Pericranial muscles including temporalis, } \\
\text { masseter, pterygoid, posterior neck muscle, } \\
\text { sternocleidomastoid, splenius or trapezius }\end{array}$ & $\begin{array}{l}\text { Localized muscle tenderness is not typical, muscle } \\
\text { tenderness may be present with long duration } \\
\text { headaches }\end{array}$ \\
\hline
\end{tabular}




\section{RECOMMENDATIONS}

\section{ASSESSMENT}

\section{Physical Examination}

1. Acute assessment focuses on determining if an individual has intracranial pathology as a consequence of the head injury. Include examination of the head and neck; cranial nerve examination including: test of olfaction, funduscopic evaluation, measurement of pupil size and reaction to light, and observation of eye movements. The examination also evaluates muscle strength and tone, gait and upper and lower extremity coordination. Warning signs of intracranial pathology that will require neurosurgical intervention include: drowsiness, impaired motor function (hemiparesis or hemi-ataxia), unsteady gait or inability to stand, vomiting with or without head pain, headache with valsalva maneuvers such as coughing, papilledema or pupil asymmetry of size or reactivity to light. Patients with warning signs of intracranial pathology need to have additional assessment including intracranial imaging.

2. As indicated in Table D-1, focal muscle contraction can be identified in some individuals with tensiontype headaches or cervicogenic pain.

\section{Medication Review}

3. Medication Review is required for people with headaches that have been present for more than two weeks and for individuals with frequent or daily headaches. Chronic use (particularly daily) of nonsteroidal anti-inflammatory drugs (NSAIDs) or acetaminophen (alone or combined with caffeine) particularly daily, may lead to rebound headaches that are similar to tension-type headaches in character. Headaches associated with chronic NSAID/acetaminophen usage should be addressed to a headache specialist. Excessive use or rapid withdrawal of caffeine or tobacco can also trigger headaches. Particular caution is required for individuals who have frequent headaches and who state that headaches respond only to opioid medications. Such individuals should be directed to a pain clinic or headache specialist.

\section{Sleep}

4. The lack of sleep can cause or exacerbate headaches and/or light sensitivity as well as problems with many cognitive/emotional functions. Ascertain current sleep/wake cycles and provide counseling regarding appropriate sleep hygiene (limiting use of stimulants, encouraging exercise, reducing presleep stimuli from lights/noise, reducing pre-sleep fluid intake, discouraging naps). Concussion is also associated with impaired sleep; i.e., disturbed abnormal breathing patterns, or disruptions in progression of sleep cycles.

\section{TREATMENT}

See table Appendix E for suggested list of selected medications used in treatment of headache

5. Pharmacotherapy and non-pharmacologic treatments to reduce the frequency of headaches and to treat acute headaches are based upon the character of the headaches. Patients who have mixed migraine/tension-like headaches may need treatment for both headache types. Based upon currently available information, most individuals with concussion/mTBI will have improvement in their headaches during the first 3 months of treatment. Consider referring patients who do not respond to treatments to headache specialists or pain treatment programs. It is important to maintain a positive outlook and to encourage active patient ownership and involvement in the care plan. It is also important to recognize co-morbid conditions, especially sleep disorders, anxiety disorders (PTSD) and depression. Treatment of these conditions may also improve headache.

\section{Episodic tension-type headaches}

6. Episodic tension-type headaches usually respond to non-steroidal anti-inflammatory medications (NSAID) that can be obtained over-the-counter. Unfortunately, tension-type headaches associated with concussion may be resistant to medication alone. Patients may achieve better pain relief if medication treatment is coupled with other treatment modalities such as relaxation training and biofeedback. Patients should be encouraged to engage in physical therapy to exercise neck muscles and maintain appropriate range of motion. Increased physical activity may help to reduce the frequency and intensity of tension headaches. These non-pharmacologic modalities may help patients 
control or moderate their headaches enabling them to gain control of their pain. NSAID medications including aspirin, ibuprofen or choline-magnesium-trisalisylate and acetaminophen are the first-line medications for treating tension headaches. The choice of an NSAID or acetaminophen depends upon individual response and severity of side effects. Aspirin is more likely to produce gastrointestinal distress and upper gastrointestinal bleeding than other NSAID medications. Acetaminophen is often the best tolerated in terms of lower likelihood to produce gastrointestinal distress. When used appropriately, side effects with acetaminophen are rare. The most serious side effect is liver damage due to large doses, chronic use or concomitant use with alcohol or other drugs that also damage the liver. Acetaminophen should be avoided in individuals with hepatitis. Choline-magnesiumtrisalisylate occasionally provides a good balance of efficacy and reduced likelihood of gastrointestinal distress. Ibuprofen can also be used to treat episodic tension headaches. If patients exhibit gastrointestinal side effects, therapy with proton-pump inhibitors and histamine blockers may be considered. Pain treatment is more likely to be successful if the medication is taken at the onset of a headache rather than waiting for the headache pain to escalate.

7. Combination medications can be effective in treating episodic tension headaches, but persistent usage can lead to rebound headaches. Aspirin, acetaminophen, or both are often combined with caffeine or a sedative drug in a single medication. Combination drugs may be more effective than NSAIDs or acetaminophen alone. Analgesic-sedative combinations can be obtained only by prescription because they may produce dependency, or trigger addiction in vulnerable individuals. This may lead to chronic daily headache. Combinations of acetaminophen or aspirin and an opioid should be used with great caution. These drugs should not be used more than two days a week due to concern for side effects and the potential for dependency.

8. Patients who experience more than three tension headaches per week may benefit from prophylactic therapy designed to prevent tension headaches. Poorly controlled tension headaches may indicate that attention should be directed to physical or psychological factors that may be triggering the headaches.

\section{Migraine Headaches}

9. Medical treatment of migraine headaches includes strategies for acute interventions and headache prevention. Many patients with migraine can be effectively treated with various acute headache medications and nonpharmacologic strategies. See Appendix E for list of pharmacologic treatments that can be used to treat and prevent migraine headaches. Patients need to be aware of factors that can trigger migraines and avoid those that trigger their headaches. Headache risk factors and triggers include: sleep disruption, delaying meals, stress, and, for some people, specific foods, beverages or odors can trigger migraine attacks. Nonpharmacologic treatments are often adjunctive to acute treatment although at times and especially early in the evolution of a migraine they may be effective and may eliminate the need for pharmacologic interventions. Nonpharmacologic treatments commonly employed are relaxation, biofeedback, visualization, extracranial pressure, and cold compresses. Regular exercise, maintaining regular sleep and meal schedules are an important part of the overall treatment regimen but are more effective as preventives than as treatments.

10. Interventions to reduce headache frequency should be considered when migraine headaches occur more than once a week or any of the following criteria exist:

a. Headache attacks that are disabling despite aggressive acute interventions

b. Patient's desire to reduce frequency of acute attacks

c. Headaches compromise work attendance, societal integration or daily life

11. Effective acute treatment requires that patients recognize their specific warning signs (aura) of an impending headache. A migraine headache often begins with mild to moderate pain that may be similar to the pain of a tension-type headache. As the migraine progresses, the headache includes the typical migraine features such as throbbing pain, nausea and phono- or photophobia. Acute treatment is more likely to succeed if medication is taken as soon as the patient recognizes the warning signs.

12. It is important that acute migraine treatment be used prudently to avoid inducing headaches due to medication overuse or rebound. Headaches associated with medication overuse are typically tensionlike in character. Treatment of medication overuse headaches requires stopping daily use of acute headache medication treatment, which will lead to withdrawal symptoms that include rebound headaches. Patients can fall into a pattern of continued medication overuse to avoid rebound 
headaches. When patients are caught in a pattern of medication-overuse, they are usually refractory to preventive medications. In most cases, headaches improve after an analgesic washout period. It is important to educate patients that acute migraine medication treatment be limited to 3 treatments a week or less on a regular basis. A headache diary including frequency and medication history use may be useful in detecting medication overuse.

13. If acute treatment of a migraine is not effective, rescue treatment may be needed to break the migraine cycle (see Table D-2). If rescue therapy is required more than once a month, then the patient should receive prophylactic treatment as well as acute treatment.

Table D - 2: Rescue interventions for migraine

\begin{tabular}{|l|l|}
\hline Intervention & Comment \\
\hline Medications & Due to nausea medications should be administered via injection or suppository \\
\hline NSAID - Ketorolac & Gastric protection against ulceration may be considered. \\
\hline $\begin{array}{l}\text { Triptans or } \\
\text { Ergotamines }\end{array}$ & $\begin{array}{l}\text { These agents are available in parenteral formulations, nasal sprays and oral tablets. } \\
\text { Given early, may abort migraine attack, may be ineffective for an advanced migraine } \\
\text { attack. }\end{array}$ \\
\hline Tramadol & The side effect of sedation can be useful as migraine attacks can abate with sleep. \\
\hline Divalproex sodium & Intravenous administration of 500mg can break a migraine \\
\hline Butorphanol (Stadol) & $\begin{array}{l}\text { This is available in a nasal inhalation formulation; given early may be able to abort a } \\
\text { migraine attack }\end{array}$ \\
\hline Opioids & $\begin{array}{l}\text { Morphine sulfate 2-4mg or comparable dose of another parenteral opioid can be useful in } \\
\text { breaking a migraine attack. Regular usage can lead to habituation. This class of } \\
\text { medications is usually avoided in mTBI patients. }\end{array}$ \\
\hline Oxygen Inhalation & $\begin{array}{l}\text { This treatment can be given in conjunction with other interventions. Oxygen is typically } \\
\text { provided as 2-4 liters per minute via nasal prongs or mask. }\end{array}$ \\
\hline Prochlorperazine & Rectal suppositories 25 mg twice daily may cause sedation \\
\hline Promethazine & Rectal suppositories 12.5-25 mg every 4-6 hours as needed may cause sedation \\
\hline
\end{tabular}




\section{D-2. Dizziness and Disequilibrium}

\section{BACKGROUND}

Dizziness and disequilibrium are common symptoms/signs of many diagnoses, concussion/mTBI being one of them. Dizziness, impaired balance and altered coordination have been reported in as many as $30 \%$ of people after mTBI (Cicerone, 1995). Dizziness and disequilibrium disorders that may result from concussion/mTBI can be organized into the following disorders: inner ear disorders (peripheral vestibular disorders), central nervous system disorders, psychological disorders and musculoskeletal disorders (see Table D-3).

Table D - 3: Criteria for categorization and referral for dizziness and disequilibrium after mTBI (Shumway-Cook, 2007; Shepard et al, 2007)

\begin{tabular}{|c|c|c|c|c|}
\hline & $\begin{array}{l}\text { Possible } \\
\text { Diagnosis }\end{array}$ & Symptoms & Duration/Provocation & Referral \\
\hline \multicolumn{5}{|c|}{ Inner Ear Disorders (Peripheral Vestibular Disorders) } \\
\hline 1 & $\begin{array}{l}\text { Benign positional } \\
\text { vertigo }\end{array}$ & $\begin{array}{l}\text { - Vertigo } \\
\text { - Lightheadedness } \\
\text { - Nausea }\end{array}$ & $\begin{array}{l}\text { - Spells that last for seconds and } \\
\text { are associated with changes in } \\
\text { head position } \\
\text { - Nystagmus usually observed } \\
\text { when symptomatic }\end{array}$ & $\begin{array}{l}\text { - Canalithic repositioning } \\
\text { maneuver } \\
\text { - Vestibular } \\
\text { Rehabilitation }\end{array}$ \\
\hline 2 & $\begin{array}{l}\text { Labyrinthine } \\
\text { Concussion }\end{array}$ & $\begin{array}{l}\text { - Vertigo with movement } \\
\text { - Disequilibrium } \\
\text { - Oscillopsia with head } \\
\text { movements } \\
\text { - Nausea \& vomiting (acute) }\end{array}$ & $\begin{array}{l}\text { - History of event, symptoms } \\
\text { improved since event but remain } \\
\text { problematic } \\
\text { - Mostly related to fast head } \\
\text { movements/turns }\end{array}$ & $\begin{array}{l}\text { - ENT } \\
\text { - Physical Therapy }\end{array}$ \\
\hline 3 & $\begin{array}{l}\text { Post-traumatic } \\
\text { endolymphatic } \\
\text { hydrops }\end{array}$ & $\begin{array}{l}\text { - Vertigo } \\
\text { - Disequilibrium } \\
\text { - Aural fullness } \\
\text { - Tinnitus }\end{array}$ & $\begin{array}{l}\text { - Spontaneous, episodic spells that } \\
\text { can last for hours }\end{array}$ & - ENT \\
\hline 4 & $\begin{array}{l}\text { Perilymphatic } \\
\text { fistula }\end{array}$ & $\begin{array}{l}\text { - Loud tinnitus } \\
\text { - Hearing loss } \\
\text { - Vertigo }\end{array}$ & $\begin{array}{l}\text { - Onset related to an event } \\
\text { - Increase in abdominal pressure } \\
\text { can elicit symptoms }\end{array}$ & - ENT \\
\hline 5 & $\begin{array}{l}\text { Bilateral } \\
\text { labyrinthine } \\
\text { dysfunction }\end{array}$ & $\begin{array}{l}\text { - Disequilibrium } \\
\text { - Vertigo \& oscillopsia if } \\
\text { lesions asymmetrical }\end{array}$ & $\begin{array}{l}\text { Related to one or more events, } \\
\text { induced by head movements, } \\
\text { difficulty with postural control in } \\
\text { the dark or on uneven surfaces }\end{array}$ & $\begin{array}{l}\text { - ENT } \\
\text { - Physical Therapy }\end{array}$ \\
\hline \multicolumn{5}{|c|}{ Central Disorder } \\
\hline 6 & $\begin{array}{l}\text { Frontal lobe } \\
\text { contusion }\end{array}$ & $\begin{array}{l}\text { - Decreased attention } \\
\text { - Impulsivity } \\
\text { - Imbalance } \\
\text { - Apraxia } \\
\end{array}$ & $\begin{array}{l}\text { - Postural issues related to } \\
\text { increased attentional demands, } \\
\text { both internal (multi-tasking) and } \\
\text { external (environmental) }\end{array}$ & $\begin{array}{l}\text { - Physiatry } \\
\text { - Physical Therapy }\end{array}$ \\
\hline 7 & $\begin{array}{l}\text { Migraine-induced } \\
\text { vestibulopathy }\end{array}$ & $\begin{array}{l}\text { - Motion sensitivity } \\
\text { - Disequilibrium } \\
\text { - Headache }\end{array}$ & $\begin{array}{l}\text { - Movement induced spells of } \\
\text { vertigo that usually last for } \\
\text { minutes to one hour, usually close } \\
\text { temporal relationship with } \\
\text { headache }\end{array}$ & $\begin{array}{l}\text { - See Section D-1: } \\
\text { Headache } \\
\text { - Physical Therapy }\end{array}$ \\
\hline 8 & Visual dysfunction & $\begin{array}{l}\text { - Dizziness } \\
\text { - Disequilibrium } \\
\text { - Blurred vision } \\
\text { - Diplopia } \\
\text { - Impaired visual-spatial } \\
\text { orientation } \\
\text { - Eye-hand incoordination } \\
\text { - Excessive peripheral vision } \\
\text { stimulation }\end{array}$ & $\begin{array}{l}\text { - Difficulties with balance on } \\
\text { uneven, conforming terrain } \\
\text { - Dizziness with increased } \\
\text { environmental stimulation } \\
\text { - Squinting/closing one eye during } \\
\text { activities } \\
\text { - Difficulty standing in midline or } \\
\text { noted head tilt }\end{array}$ & $\begin{array}{l}\text { - Ophthalmology } \\
\text { - Vision Rehabilitation }\end{array}$ \\
\hline
\end{tabular}




\begin{tabular}{|c|c|c|c|c|}
\hline & $\begin{array}{l}\text { Possible } \\
\text { Diagnosis }\end{array}$ & Symptoms & Duration/Provocation & Referral \\
\hline \multicolumn{5}{|c|}{ Psychological Disorder } \\
\hline 9 & $\begin{array}{l}\text { Depression, } \\
\text { anxiety, } \\
\text { somatization }\end{array}$ & $\begin{array}{l}\text { - Lightheadedness } \\
\text { - Floating } \\
\text { - Rocking } \\
\text { - Vague/bizarre accounts }\end{array}$ & $\begin{array}{l}\text { - May be related to event but could } \\
\text { report chronic history, symptoms } \\
\text { can be induced by eye movments } \\
\text { with head still }\end{array}$ & $\begin{array}{l}\text { - Psychiatry } \\
\text { - Psychology } \\
\text { - Physical Therapy }\end{array}$ \\
\hline \multicolumn{5}{|c|}{ Musculoskeletal Disorder } \\
\hline 10 & $\begin{array}{l}\text { Flexion-extension, } \\
\text { cervical injury } \\
\text { (cervicogenic) }\end{array}$ & $\begin{array}{l}\text { - Vertigo } \\
\text { - Disequilibrium } \\
\text { - Lightheadedness } \\
\text { - Neck pain }\end{array}$ & $\begin{array}{l}\text { - Onset with event } \\
\text { - Symptoms coincide with } \\
\text { movement of cervical spine }\end{array}$ & $\begin{array}{l}\text { - Physiatry } \\
\text { - Physical Therapy }\end{array}$ \\
\hline \multicolumn{5}{|c|}{ Uncommon Central Disorders } \\
\hline 11 & $\begin{array}{l}\text { Brain stem or } \\
\text { cerebellar } \\
\text { dysfunction }\end{array}$ & $\begin{array}{l}\text { - Vertigo } \\
\text { - Disequilibrium } \\
\text { - Nausea \& Vomiting } \\
\text { - Head/trunk tilt } \\
\text { - Lateropulsion } \\
\text { - Ataxia } \\
\text { - Sensory disturbance } \\
\text { - Oscillopsia } \\
\text { - Vision deficits } \\
\text { - Incoordination }\end{array}$ & $\begin{array}{l}\text { - Onset with event } \\
\text { - Can be exacerbated by movement }\end{array}$ & $\begin{array}{l}\text { - Neurology } \\
\text { - Physical Therapy } \\
\text { - Ophthalmology } \\
\text { - Vision Rehabilitation }\end{array}$ \\
\hline 12 & $\begin{array}{l}\text { Vertebral-basilar } \\
\text { insufficiency } \\
\text { related to } \\
\text { occipitoatlantal } \\
\text { instability }\end{array}$ & $\begin{array}{l}\text { - Nausea \& vomiting } \\
\text { - Vertigo } \\
\text { - Visual hallucinations/ loss } \\
\text { - Visual field deficit } \\
\text { - Numbness/weakness } \\
\text { - Ataxia } \\
\text { - Drop attacks } \\
\text { - Diplopia } \\
\text { - Headaches }\end{array}$ & $\begin{array}{l}\text { - Related to an event } \\
\text { - Usually symptoms induced by } \\
\text { cervical extension and rotation }\end{array}$ & $\begin{array}{l}\text { - Neurology } \\
\text { - Neurosurgery }\end{array}$ \\
\hline 13 & $\begin{array}{l}\text { Temporal bone } \\
\text { fracture }\end{array}$ & $\begin{array}{l}\text { - Conductive hearing loss } \\
\text { - Vertigo } \\
\text { - Disequilibrium } \\
\text { - Nausea \& vomiting } \\
\text { - Oscillopsia } \\
\end{array}$ & $\begin{array}{l}\text { - Onset with event } \\
\text { - Will follow the course of } \\
\text { labyrinthine concussion }\end{array}$ & $\begin{array}{l}\text { - ENT } \\
\text { - Physical Therapy }\end{array}$ \\
\hline
\end{tabular}

\section{RECOMMENDATIONS}

\section{ASSESSMENT}

\section{Physical Examination}

1. Observation and patient interview are key elements to the exam and often guide the clinician in determining the plan of care. Evaluation should include a thorough neurologic examination and the following systems review: vision (acuity, tracking, saccades, nystagmus), auditory (hearing screen, otoscopic exam), sensory (sharp, light touch, proprioception, vibration), motor (power, coordination) and vestibular (dynamic acuity, positional testing). Evaluation of functional activities should include sitting and standing (Romberg with eyes open/closed, single leg stance) balance, transfers (supine $\leftrightarrow$ sit, sit $\leftrightarrow$ stand) and gait (walking, tandem walking, turning).

\section{Medication Review}

2. A detailed medication history is warranted. Numerous medications include dizziness as a potential side effect. The following classes of medication can cause or aggravate dizziness: stimulants, 
benzodiazepines, tricyclics, monoamine oxidase inhibitors, tetracyclics, neuroleptics, anticonvulsants, selective serotonin agonists, beta blockers and cholinesterase inhibitors. The temporal relationship to the onset of dizziness and the initiation/dosing of these medications should be investigated.

\section{TREATMENT}

\section{Pharmacologic Treatment}

3. Initiating vestibular suppressants for dizziness may delay central compensation or promote counterproductive compensation (Hain \& Yacovino, 2005; Pyykko I, 1988). Vestibular suppressants might be helpful during the acute period of several vestibular disorders but have not been shown to be effective in chronic dizziness after concussion (Zee, 1985). Medications should only be considered if symptoms are severe enough to significantly limit functional activities. Trials should be limited to 2 weeks. With concussion/mTBI be particularly careful regarding dosing and titration due to the effects on arousal and memory as well as potential addictive qualities of these medications (Arciniegas, 2005). First line medication choice would be meclizine, followed by scopolamine and dimenhydrinate depending upon symptom presentation. Pharmacotherapy with clonazepam, diazepam or lorazepam should be carefully considered due to their sedating and addictive qualities. (See Table D-6)

\section{Non-Pharmacologic Treatment}

4. Non-pharmacologic interventions for post-traumatic dizziness may be useful as an alternative to pharmacotherapies (de Kruijk et al., 2002), although the effectiveness of such interventions is not fully established with concussion/mTBI. Efficacy of vestibular and balance rehabilitation has been found in different populations with vestibular disorders (Herdman et al., 1995; Shepard \& Telian, 1995; Yardley et al., 1998). Patients with vestibular disorders who received customized programs showed greater improvement than those who received generic exercises (Shepard \& Telian, 1995). Studies utilizing vestibular exercises have shown up to $85 \%$ success rate in reducing symptoms and improving function in the population with peripheral vestibular disorders (Krebs et al, 2003; Shepard \& Telian, 1995). With concussion/mTBI, recovery of vestibular lesions is often limited or protracted due to the coexistence of central or psychological disorders (Gottshall et al., 2007).

5. Knowledge of the canalith repositioning procedures (Fife, 2008) for the treatment of benign positional vertigo would be beneficial for primary care physicians. The types of exercise to treat dizziness and disequilibrium are beyond the scope of this guideline. Central and psychological disorders need a coordinated team effort to address the underlying impairments to maximize outcome of vestibular rehabilitation.

\section{D-3. Fatigue}

BACKGROUND

Fatigue is the third most common symptom reported in concussion/mTBI. It can be due to a primary effect related to central nervous system dysfunction or a secondary effect such as common co-existing disorders in concussion/mTBI such as depression or sleep disturbances. Medications, substance use and lifestyle may also contribute to fatigue. 
Table D - 4: Criteria for characterizing Fatigue

\begin{tabular}{|l|l|l|}
\hline Effect & Assessment & Treatment \\
\hline $\begin{array}{l}\text { Metabolic (uncommon } \\
\text { in concussion/mTBI) }\end{array}$ & Positive lab findings & Further medical evaluation \\
\hline Physical & $\begin{array}{l}\text { Usually subjective, state of weariness related } \\
\text { to physical exertion resulting in diminished } \\
\text { capacity for work or decreased response to } \\
\text { stimuli }\end{array}$ & Individualized fitness program \\
\hline Cognitive & $\begin{array}{l}\text { Usually subjective, state of weariness related } \\
\text { to increased mental effort resulting in } \\
\text { diminished capacity for work or decreased } \\
\text { response to stimuli }\end{array}$ & $\begin{array}{l}\text { Cognitive rehabilitation } \\
\text { (Educational Programming, } \\
\text { Cognitive Behavioral Therapy) }\end{array}$ \\
\hline Sleep Disturbance & $\begin{array}{l}\text { Self-reported, } \\
\text { Positive sleep studies }\end{array}$ & See section D-4 Sleep Disorder \\
\hline Depression & Depression screen & $\begin{array}{l}\text { See Algorithm C: Persistent } \\
\text { Emotional and cognitive } \\
\text { Symptom management }\end{array}$ \\
\hline
\end{tabular}

RECOMMENDATIONS

\section{ASSESSMENT}

1. A detailed history looking at pre/post-injury level of physical activity, cognitive function and mental health is important to determine the effects of fatigue in relation to the injury. The ability to maintain a job is often a good measure of the impact of this symptom. Several outcome measures exist for fatigue and many have been studied in other diagnostic populations. Common measures in TBI include the Multidimensional Assessment of Fatigue (MAF), Fatigue Impact Scale (FIS) or Fatigue Assessment Instrument (FAI.) For concussion/mTBI there is no specific scale recommended. Laboratory tests may include blood count, metabolic panel, vitamin B12 and folate levels, thyroid function test and Erythrocyte Sedimentation Rate (ESR).

\section{MEDICATION REVIEW}

2. Due to the large number of centrally acting medications, a medication review is necessary. If a medication appears contributory, performance of an Applied Behavioral Analysis (ABA) trial is indicated to determine the association. Review of illicit drugs, alcohol, tobacco and caffeine/other stimulants should be performed.

\section{TREATMENT}

\section{Pharmacologic treatment}

3. All medical and psychological disorders underlying fatigue should be treated. Modifiable factors should be addressed and typical conservative measures taken prior to initiating pharmacotherapy for fatigue. Several stimulants have had success in other disease states associated with fatigue. Although widely used in TBI, there is limited evidence in use of these medications for treatment of fatigue in concussion/mTBI.

If symptoms have persisted for more than 4 weeks post-injury and the fatigue level has not improved with the management of sleep, pain, depression, or lifestyle, then a neurostimulant may be tried. (See Appendix E)

Medication trials should persist for at least 3 months. Use of neurostimulant medications is contraindicated if there is a history of substance abuse.

\section{Non-pharmacologic treatment}

4. Education is important in the treatment of fatigue. Educational efforts should be in the areas of factors contributing to fatigue, importance of well balanced meals, promotion of sleep hygiene and regular 
exercise. Exercise routines should be individualized to maximize benefit and promote proper ratio of activity/rest. Scheduling of exercise may need to be addressed depending upon when the patient is at his or her best. Cognitive-behavioral and physical therapy can be tried to decrease fatigue level and improve functional performance in patients with concussion/mTBI.

\section{D-4. Sleep Dysfunction}

\section{BACKGROUND}

Sleep disturbance often occurs acutely after concussion. Persistent difficulty falling asleep or staying asleep despite the opportunity (insomnia) is a common symptom of post trauma. Concussion/mTBI might contribute to the emergence of circadian rhythm sleep disorders. Two types of these disorders have been observed: delayed sleep phase syndrome and irregular sleep-wake pattern. Sleep apnea, depression, pain, and other conditions may contribute to the overall poor quality of sleep. (See Table D-5 Management of Sleep Dysfunction)

\section{RECOMMENDATIONS}

1. Pharmacological approaches to sleep regulation may prove beneficial. (See Appendix E)

2. Cognitive behavioral sleep interventions have also been shown to be effective in normalizing sleep, these might include sleep restriction, sleep hygiene education, relaxation training and others. The goals of sleep management should be to establish a regular, unbroken, night-time sleep pattern and to improve perceptions of the quality of sleep.

3. If a patient with concussion/mTBI has a concurrent primary sleep disorder (e.g., sleep apnea, restless leg syndrome, or narcolepsy) a specific appropriate intervention may be required.

4. The aim of sleep management is to establish a regular, normalized sleep-wake pattern. Patients should be encouraged to:

- Avoid alcohol

- Restrict the night-time sleep period to about eight hours

- Avoid going to bed too early in the evening

- Avoid stimulants, caffeinated beverages, power drinks, and nicotine during the evening period

- Arise from bed at a regular time in the morning (e.g., by 8 a.m.)

- Wake at a regular time in the morning (e.g., 7 a.m.)

- Reduce (to less than 30 minutes) or abolish daytime naps

- Engage in daytime physical and mental activities (within the limits of the individual's functional capacity)

- Avoid stimulating activities before bedtime (e.g., exercise, video games, T.V.) 
Table D - 5: Management of Sleep Dysfunction

\begin{tabular}{|c|c|}
\hline Acute Phase & Chronic Phase (>3 months). \\
\hline $\begin{array}{l}\text { Provide education about concussion with } \\
\text { regard to changes in sleep quality and } \\
\text { duration sometimes associated with } \\
\text { concussion. } \\
\text { - Provide information on good sleep habits } \\
\text { with specific suggestions to improve the } \\
\text { quality and duration of sleep, e.g., regularly } \\
\text { scheduled bedtime. } \\
\text { - Provide information about the potential } \\
\text { effects of medications, caffeine, tobacco, and } \\
\text { alcohol on sleep. } \\
\text { - Sleep medications may be helpful in the } \\
\text { short-term (non-benzodiapenes). }\end{array}$ & $\begin{array}{l}\text { - Review current medications and other current } \\
\text { health conditions for factors which might } \\
\text { contribute to chronic sleep disturbances, } \\
\text { including chronic pain. Provide information } \\
\text { about the potential effects of medications, } \\
\text { caffeine, tobacco, and alcohol on sleep. } \\
\text { - Evaluate for potential co-morbid psychiatric } \\
\text { conditions, including depression and anxiety and, } \\
\text { if present, consider using standard medications } \\
\text { which may improve sleep. } \\
\text { - If patient has a chronic pain disorder, appropriate } \\
\text { pain management may assist with improving } \\
\text { sleep duration and quality. } \\
\text { - Consider sleep study to provide objective } \\
\text { evidence of sleep disturbance and to rule out co- } \\
\text { existing sleep apnea or other sleep disorders. } \\
\text { - Training in behavioral techniques, such as } \\
\text { relaxation training or meditation to improve the } \\
\text { quality of sleep. } \\
\text { - Consider a course of Cognitive Behavioral } \\
\text { Therapy (CBT) focused on sleep with additional } \\
\text { behavioral interventions to include Sleep } \\
\text { Restriction, Stimulus Control and Relapse } \\
\text { Prevention Techniques. }\end{array}$ \\
\hline
\end{tabular}

For additional recommendations - See VHA Pharnacy Benefit Management (PBM) guideline for Insomnia:

http://www.pbm.va.gov/guidelines/Treatment\%20of\%20Acute-Chronic\%20InsomniaGuidance\%20for\%20Tx\%20of\%20Insomnia\%20in\%20Primary\%20Care $\% 20$ Setting -Recommendation\%20for\%20Use\%20Zolpidem\%20IR.doc

\section{Patient Resources for Basic Hygiene Education}

http://www.womenshealth.gov/faq/insomnia.htm\#5

http://www.aasmnet.org/FactSheet.aspx

http://www.sleepfoundation.org/

\section{Example of a sleep diary:}

http://www.nhlbi.nih.gov/health/prof/sleep/insom_pc.pdf

\section{Professional Education:}

http://www.sleepfoundation.org/

http://www.ahrq.gov/clinic/epcsums/insomnsum.htm 


\section{D-5. Persistent Pain}

(See also D-1 for a complete discussion of headache pain)

\section{BACKGROUND}

Pain other than headache pain is common in patients with concussion/mTBI. Musculoskeletal pain is a common comorbid condition in concussion. Evaluating pain and treating it symptomatically is important as pain is associated with poor outcomes in TBI. Pain can be caused by any of a number of co-morbid conditions as well as musculoskeletal injuries or secondary damage to soft tissue.

Assessing patients for pain and its underlying causes is an essential component of the clinical work-up. It is important to attribute symptoms correctly and to identify and treat any comorbid conditions. If medication is being considered, it is essential that the underlying cause has been established prior to prescribing.

\section{RECOMMENDATIONS}

1. Pain management must be a priority and all patients presenting with concussion should be assessed for pain on a regular basis.

2. Choice of treatment modalities for patients with concussion should be based upon risk benefit.

3. Pain management for patients with concussion should be based on a patient-centered model of care.

4. A pain management plan must consider the causation, psychosocial factors and general physical condition of the patient with concussion.

5. Effective drugs for pain relief for the patient with concussion include nonsteroidal anti-inflammatory drugs (NSAIDs), or muscle relaxants.

6. Physical therapy may be beneficial in conjunction with medications for the patient with concussion.

\section{D6. Management of other Symptoms}

The following recommendations for treatment of other physical symptoms, less common in patients presenting with concussion/mTBI symptoms, were formulated based on consensus of clinical experts.

\section{Vision Difficulties}

\section{BACKGROUND}

Vision difficulties, including sensitivity to light, diplopia, blurring and other difficulties seeing, occur acutely in up to half of all individuals who sustain a concussion. Symptoms are either blurring of vision ("double vision") that worsens over the course of the day or difficulty with visual stimulation with resultant pain (headache, eye ache) or sensitivity. The vast majority resolve within a month. Aggressive, focal treatments aimed at symptom management (reassurance, pain management, controlling environmental light, sunglasses, intermittent patching for double vision) in the first 4-6 weeks are usually effective. True abnormalities in visual acuity, visual fields or structural damage the eye are extremely rare with mTBI. Other causes of problems are also extremely rare and often not related directly to the concussion injury. Pre-injury visual deficits are common and need to be ruled out.

\section{RECOMMENDATIONS}

1. Perform an ophthalmologic examination to include extraocular movements, pupils and visual fields by confrontation.

2. Refer to optometry and/or ophthalmology as indicated.

3. Allow initial use (until in therapy) of sunglasses and then give formal weaning program (decrease by 15 minutes every 2 hours). 
4. Consider non-organic vision loss in patients who present with prolonged sunglass use even in low light settings.

\section{Hearing Difficulties}

BACKGROUND

Hearing difficulties, including altered acuity and sensitivity to noise, occur acutely in up to threequarters of all individuals who sustain a blast related concussion. Symptoms are either of decreased auditory acuity or sensitivity to noise. The vast majority of those symptoms resolve within a month, unless there is significant or permanent injury to the ear drum. Aggressive, focal treatments aimed at symptom management (reassurance, pain management, controlling environmental noise, white noise generators) in the first 4-6 weeks are usually effective. True abnormalities in central auditory acuity or processing are extremely rare with mTBI. Other causes of problems are also extremely rare and often not related directly to the concussion injury. Pre-injury hearing deficits are common and need to be ruled out.

RECOMMENDATIONS

1. Perform an otologic examination.

2. Review medications for ototoxicity.

3. Refer to audiology for hearing assessment if no other apparent cause is found.

\section{Smell (Olfactory Deficits)}

\section{BACKGROUND}

Post-traumatic olfactory deficits (anosmia) are not common in individuals who sustain a concussion, occurring in less than $25 \%$. Symptoms are typically seen with a decreased appetite, but this may be a sign of a significant injury to the frontal lobe and other central difficulties must be ruled out. The vast majority resolve within a 6 month period. Treatments have limited effect and are usually aimed at flavoring/spicing food to enhance taste. Other causes are also extremely rare and often not related directly to the concussion injury. Pre-injury causes of anosmia need to be ruled out.

\section{RECOMMENDATIONS}

1. Perform a nasal and oropharyngeal examination and depression screen.

2. Refer to ENT for further evaluation if needed.

3. If neurologic status is stable and no objective findings then reassurance and monitoring is appropriate. Increase spicing of foods ( $+/$ - dietary referral). Monitor weights.

\section{Changes in Appetite}

\section{BACKGROUND}

Post-traumatic appetite deficits are not common in individuals who sustain a concussion, occurring in less than $5 \%$. When a change in appetite is noted, it may be related to mood, medications, smell, or other factors and will likely resolve. Treatments have limited effect and are usually aimed at flavoring/spicing food to enhance taste or managing depression. Other causes are also extremely rare and often not related directly to the concussion injury. Pre-injury causes of appetite issues need to be ruled out.

RECOMMENDATIONS

1. Perform nasal and oropharyngeal examination. 
2. Review neurovegetative signs with patient to assess for depressed affect or clinical depression.

3. Assess medication list for agents that can cause olfactory or gustatory abnormalities (centrally acting medications, in particular anti-epileptics, some antibiotics).

4. If neurologic status is stable and no objective findings then reassurance and monitoring is appropriate. Increase spicing of foods (+/- dietary referral). Monitor weights.

\section{Numbness}

It is extremely rare to see numbness with mTBI in the absence of peripheral nerve injury, and it usually represents somatization. If neurologic status is stable and no objective findings then reassurance and monitoring is appropriate.

RECOMMENDATION

1. Perform a sensory examination.

\section{Nausea}

BACKGROUND

Post-traumatic nausea occurs occasionally acutely after concussion, most often in combination with dizziness, as a secondary effect of medications (pain), or due to an exacerbation of underlying GERD/GI dysfunction. Assessment initially is limited and focus should be on rapid management of dizziness and return to activity.

\section{RECOMMENDATIONS}

1. Define triggers and patterns of nausea.

2. Assess medication list for agents that may cause or worsen GI symptoms.

3. Perform oropharyngeal examination. 


\section{Appendix E: Pharmacotherapy}

\section{Pharmacotherapy in Concussion/mTBI - List of Selected First line Agents}

\begin{tabular}{|c|c|c|c|}
\hline & Potential Side Effects & $\begin{array}{l}\text { Contraindications/ } \\
\text { Comments }\end{array}$ & $\begin{array}{l}\text { Common Issues In } \\
\text { Concussion/Mtbi }\end{array}$ \\
\hline \multicolumn{4}{|c|}{ Stimulants (In specialty care after ruling out sleep disorder.) } \\
\hline $\begin{array}{l}\text { First line agents: } \\
\text { Methylphenidate } 5 \text { mg every } 8 \text { am and } 1 \\
\text { pm, increasing total daily dose by } 5 \\
\text { mg every } 2 \text { weeks to a maximum of } \\
20 \text { mg twice daily }\end{array}$ & $\begin{array}{l}\text { - Insomnia } \\
\text { - Decreased appetite } \\
\text { - GI upset } \\
\text { - Headaches } \\
\text { - Dizziness } \\
\text { - Motor tics } \\
\text { - Irritability } \\
\text { - Anxiousness } \\
\text { - Tearfulness }\end{array}$ & $\begin{array}{l}\text { Ongoing substance } \\
\text { abuse. }\end{array}$ & $\begin{array}{l}\text { Possible addiction } \\
\text { potential } \\
\text { Requires additional } \\
\text { prescription regulation } \\
\text { under federal/state law. } \\
\text { Cannot be refilled, only } \\
\text { one month of therapy at a } \\
\text { time may be prescribed }\end{array}$ \\
\hline $\begin{array}{l}\text { Modafanil start with } 100 \mathrm{mg} \text { every } \\
\text { morning. Increase in } 100 \mathrm{mg} \\
\text { amounts, using split daily dosing up } \\
\text { to maximum of } 400 \mathrm{mg} / \text { day }\end{array}$ & - Headache, asthesia & & \\
\hline Amantadine $100-400 \mathrm{mg}$ daily & $\begin{array}{l}\text { - Nausea } \\
\text { - Dizziness } \\
\text { - Dry mouth }\end{array}$ & & \\
\hline \multicolumn{4}{|l|}{ Antidepressants } \\
\hline $\begin{array}{l}\text { First line agents: } \\
\text { Citalopram } 10 \mathrm{mg} \text { daily for } 1 \text { week, then } \\
20 \mathrm{mg} \text { daily if tolerated (up to } 80 \\
\mathrm{mg} \text { daily if needed) } \\
\text { Sertraline } 25 \mathrm{mg} \text { daily increasing weekly } \\
\text { in } 25 \mathrm{mg} \text { increments to maximum } \\
\text { dose of } 200 \mathrm{mg} / \text { day }\end{array}$ & $\begin{array}{l}\text { - Nausea } \\
\text { - Insomnia } \\
\text { - Agitation } \\
\text { - Asthesia } \\
\text { - Nausea } \\
\text { - Insomnia } \\
\text { - Dry mouth } \\
\text { - Headache }\end{array}$ & $\begin{array}{l}\text { Do not initiate } \\
\text { concomitant therapy } \\
\text { with a benzodiazepine }\end{array}$ & $\begin{array}{l}\text { May cause sexual } \\
\text { dysfunction }\end{array}$ \\
\hline \multicolumn{4}{|l|}{ Non-benzodiazepine Sleep Agents } \\
\hline $\begin{array}{l}\text { First line agent: } \\
\text { Zolpidem } 5 \mathrm{mg} \text { at night, if poor results after } \\
3 \text { nights of therapy increase to } 10 \\
\text { mg nightly }\end{array}$ & & & \\
\hline $\begin{array}{l}\text { Prazosin initiate therapy with } 1 \mathrm{mg} \text { at } \\
\text { bedtime for three days. } \\
\text { May increase to } 2 \mathrm{mg} \text { at bedtime } \\
\text { through day } 7 \text {. If patients } \\
\text { continued to have nightmares, the } \\
\text { dosage may be increased to } 4 \mathrm{mg} \\
\text { at bedtime through day } 14 \text {. The } \\
\text { dosage could be increased to } 6 \mathrm{mg} \\
\text { at bedtime through day } 21 \text { and to } \\
10 \text { mg at bedtime through day } 28 . \\
\text { The maximum daily dose is } 10 \mathrm{mg} \\
\text { at bedtime. }\end{array}$ & - Orthostatic hypotension & & $\begin{array}{l}\text { For patients with } \\
\text { nightmares and/or violent } \\
\text { or outburst or or agitation } \\
\text { during sleep }\end{array}$ \\
\hline
\end{tabular}




\begin{tabular}{|c|c|c|c|}
\hline & Potential Side Effects & $\begin{array}{l}\text { Contraindications/ } \\
\text { Comments }\end{array}$ & $\begin{array}{l}\text { Common Issues In } \\
\text { Concussion/Mtbi }\end{array}$ \\
\hline \multicolumn{4}{|l|}{ NSAIDS for headache } \\
\hline $\begin{array}{l}\text { Ibuprofen } 400-600 \mathrm{mg} \text { three to four times } \\
\text { daily } \\
\text { Naproxen } 500 \mathrm{mg} \text { twice daily }\end{array}$ & $\begin{array}{l}\text { - } \text { GI upset } \\
\text { - Dizziness } \\
\text { - } \text { vertigo }\end{array}$ & & $\begin{array}{l}\text { Potential renal impairment } \\
\text { with long term use } \\
\text { Rebound headache may } \\
\text { occur with continuous use }\end{array}$ \\
\hline \multicolumn{4}{|c|}{ Abortive Agents For Migraine/Migraine-Like Headaches } \\
\hline $\begin{array}{l}\text { Zolmitriptan oral } 5-10 \mathrm{mg} \text { at onset of } \\
\text { headache, may repeat once if } \\
\text { headache is not resolved in } 2 \text { hours } \\
\text { Zolmitriptan nasal one spray of } 5 \mathrm{mg} \text { for } \\
\text { the treatment of acute migraine. If } \\
\text { the headache returns the dose may } \\
\text { be repeated after } 2 \text { hours. The } \\
\text { maximum daily dose should not } \\
\text { exceed } 10 \text { mg in any } 24 \text {-hour period } \\
\text { Sumatriptan oral } 50-100 \text { mg at onset of } \\
\text { headache, may repeat once if } \\
\text { headache is not resolved in } 2 \text { hours } \\
\text { Sumatriptan nasal } 10 \text { mg spray in one } \\
\text { nostril, may repeat in } 2 \text { hrs not to } \\
\text { exceed } 40 \text { mg/day } \\
\text { Sumatriptan injectable } 6 \text { mg injected } \\
\text { subcutaneously may repeat in } 1 \\
\text { hour. Not to exceed } 12 \text { mg/day }\end{array}$ & $\begin{array}{l}\text { - unusual taste (nasal } \\
\text { formulation), } \\
\text { paresthesia, } \\
\text { hyperesthesia, dizziness, } \\
\text { chest tightness } \\
\text { - Dizziness, vertigo, } \\
\text { tingling, hypertension, } \\
\text { injection site reactions, }\end{array}$ & & $\begin{array}{l}\text { Serious cardiac events, } \\
\text { including myocardial } \\
\text { infarction, have occurred } \\
\text { following the use of } \\
\text { zolmitriptan and } \\
\text { sumatriptan tablets and } \\
\text { nasal spray. These events } \\
\text { are extremely rare and } \\
\text { most have been reported } \\
\text { in patients with risk } \\
\text { factors predictive of CAD }\end{array}$ \\
\hline \multicolumn{4}{|l|}{ Prophylactic Headache Agents } \\
\hline $\begin{array}{c}\text { First line agents: } \\
\text { Divalproex sodium extended release } 250 \\
\mathrm{mg} \text { twice daily, increase by } 250 \\
\mathrm{mg} / \text { day every week to a maximum } \\
\text { of } 1000 \mathrm{mg} / \text { day }\end{array}$ & $\begin{array}{l}\text { Asthenia, dizziness, } \\
\text { somnolence, tremor, } \\
\text { nausea, diplopia }\end{array}$ & $\begin{array}{l}\text { Hepatic failure } \\
\text { resulting in fatalities } \\
\text { has occurred in patients } \\
\text { receiving valproic acid } \\
\text { and its derivatives }\end{array}$ & $\begin{array}{l}\text { May take up to } 3 \text { months } \\
\text { to receive the full benefit } \\
\text { from any of the } \\
\text { prophylactic medications } \\
\text { Association with } \\
\text { teratogenecity, neural tube } \\
\text { effects. Caution in women } \\
\text { of childbearing potential }\end{array}$ \\
\hline Topiramate $25-100 \mathrm{mg}$ twice daily & $\begin{array}{l}\text { - Anorexia, sedation, } \\
\text { ataxia, dizziness }\end{array}$ & & $\begin{array}{l}\text { May worsen cognitive } \\
\text { dysfunction } \\
\text { May cause renal stones }\end{array}$ \\
\hline $\begin{array}{l}\text { Metoprolol initiate with } 25 \mathrm{mg} \text { twice daily, } \\
\text { increase dose up to } 100 \mathrm{mg} \text { twice } \\
\text { daily if needed, wait } 3-4 \text { weeks } \\
\text { between dose increases }\end{array}$ & $\begin{array}{l}\text { - Somnolence } \\
\text { - Cold extremities } \\
\text { - bradycardia }\end{array}$ & $\begin{array}{l}\text { There are two } \\
\text { formulations- tartrate } \\
\text { is immediate release, } \\
\text { dosed } 2 \text { times daily and } \\
\text { succinate is sustained } \\
\text { release, dosed one time } \\
\text { daily. }\end{array}$ & $\begin{array}{l}\text { Use with caution in } \\
\text { asthmatic and diabetic } \\
\text { patients }\end{array}$ \\
\hline
\end{tabular}




\begin{tabular}{|c|c|c|c|}
\hline & Potential Side Effects & $\begin{array}{l}\text { Contraindications/ } \\
\text { Comments }\end{array}$ & $\begin{array}{l}\text { Common Issues In } \\
\text { Concussion/Mtbi }\end{array}$ \\
\hline \multicolumn{4}{|l|}{ Vestibular Suppressants } \\
\hline Meclizine $12.5-50 \mathrm{mg}$ every 4-6 hours & $\begin{array}{l}\text { - Hallucinations, blurred } \\
\text { vision }\end{array}$ & \multirow{4}{*}{$\begin{array}{l}\text { All of the agents may } \\
\text { cause sedation and } \\
\text { require caution when } \\
\text { driving or operating } \\
\text { machinery }\end{array}$} & \\
\hline Scopolamine $0.5 \mathrm{mg}$ patch every 3 days & $\begin{array}{l}\text { - Dry mouth } \\
\text { - Topical Allergy } \\
\text { - Tachyarrhythmia }\end{array}$ & & \\
\hline $\begin{array}{l}\text { Dimenhydrinate } 50 \mathrm{mg} \text { every } 4-6 \text { hours } \\
\text { orally }\end{array}$ & - Dry mouth & & \\
\hline $\begin{array}{l}\text { Lorazepam } 0.5 \mathrm{mg} \text { twice a day orally } \\
\text { Clonazepam } 0.25-0.5 \mathrm{mg} \text { twice a day } \\
\quad \text { orally } \\
\text { Diazepam } 2-10 \mathrm{mg} \text { orally, IM, or IV }\end{array}$ & $\begin{array}{l}\text { - Drug dependence } \\
\text { - Respiratory depressant }\end{array}$ & & $\begin{array}{l}\text { Avoid use of } \\
\text { benzodiazapines in mTBI } \\
\text { if at all possible }\end{array}$ \\
\hline
\end{tabular}




\section{Appendix G: Acronym List}

\begin{tabular}{|l|l|}
\hline ACRM & American College of Rehabilitation Medicine \\
\hline ADL & Activities of Daily Living \\
\hline ATC & Assistive Technology for Cognition \\
\hline AOC & Alteration of Consciousness/Mental State \\
\hline CAM & Complementary Alternative Medicine \\
\hline CDC & Centers for Disease Control and Prevention \\
\hline CT & Computed Tomography \\
\hline DVBIC & Defense and Veterans Brain Injury Center \\
\hline DSM-IV & Diagnostic and Statistical Manual for Mental Disorders - Fourth Edition \\
\hline GCS & Glasgow Coma Score \\
\hline IADL & Instrumental Activities of Daily Living \\
\hline ICD-10 & International Classification of Diseases - 10th Revision \\
\hline LOC & Level of Consciousness \\
\hline MSA & Mental Status Examination \\
\hline mTBI & Mild Traumatic Brain Injury \\
\hline PCD & Post-Concussion Disorder \\
\hline PCS & Post-Concussion Syndrome or Post Concussive Syndrome \\
\hline PPCS & Persistent Post Concussive Symptoms \\
\hline PTA & Post-Traumatic Amnesia \\
\hline PTSD & Post-Traumatic Stress Disorder \\
\hline OIF/OEF & Operations Iraqi Freedom and Enduring Freedom \\
\hline SR & Strength of the Recommendation \\
\hline USPSTF & United States Preventative Services Task Force \\
\hline WHO & World Health Organization \\
\hline
\end{tabular}

